\title{
COMPARATIVE ANALYSIS OF THE INFLUENCE OF CREEP OF CONCRETE COMPOSITE BEAMS OF STEEL - CONCRETE MODEL BASED ON VOLTERRA INTEGRAL EQUATION
}

\section{KOMPARATIVNA ANALIZA UTICAJA TEČENJA BETONA SPREGNUTE GREDE ČELIK - BETON MODELIMA ZASNOVANIM NA INTEGRALNOJ JEDNAČINI VOLTERRA}

\author{
Doncho PARTOV \\ Vesselin KANTCHEV
}

ORIGINALNI NAUČNI RAD

ORIGINAL SCIENTIFIC PAPER

UDK: $624.044: 539.42$

doi:10.5937/grmk1702003P

\section{INTRODUCTION}

Steel-concrete composite beams are widely spread form of construction in both buildings and bridges, (Cosenza and Zandonini 1999; Dujmović, Androić, and Lukačević, 2015; Folić and Zenuvović 2009; Johnson 2004; Oehlers and Bradford 1999; Vayas and Iliopoulos 2014, Wang 2002). The time-varying behaviour of composite steel-concrete members under sustained service loads drawn the attention of engineers who were dealing with the problems of their design more than 60 years. Creep has a considerable impact upon the performance of composite beams, causing increased deflection as well as affecting stress distribution. Creep in concrete represents dimensional change in the material under the influence of sustained loading. Failure to include creep effects in the analysis of the composite steel-concrete beams may lead to excessive deformation and cause significant redistribution of stress between concrete plate and steel beam. In general, time-dependent deformation of concrete regarding creep phenomena may severely affect the serviceability, durability and stability of structures. Creep analysis of composite structures is normally performed on the basis of the linear theory of viscoelasticity for aging materials.

Corresponding author, Professor Dr. Doncho Partov, of structural mechanics at the University of Structural Engineering and Architecture "L.Karavelov" in Sofia, Bulgaria

${ }^{2}$ Dr. Vesselin Kantchev, Associate professor of

mathematics at the University of Structural Engineering and Architecture "L.Karavelov" in Sofia, Bulgaria
A large number of practical problems concerning the influence of creep effect on the reliability and durability of concrete and composite structures can be solved exactly through four fundamental theorems of this theory, as demonstrated by (Chiorino et al. 2010). These compact formulations are particularly suitable for codes and technical guidance documents (CEN 2004a, CEN 2004b), and helpful in the global assessment of creep induced structural effect in the preliminary design stages, as well as in the control of the output of the detailed numerical investigations and safety checks.

In this paper we try to make the comparison in results, obtained from Eurocode 2(Comité Européen de Normalisation[CEN], 2004a), ACl209-R2(ACI Committee 209, 2008), and G\&L(Gardner and Lockman 2001), models in numerical creep analysis of composite steel concrete beams. Before that we try to introduce the fundamentals of linear viscoelasticity of aging materials applied to concrete in the light of the great international school of hereditary mechanics of: Northwest University in USA present of (Bažant et al. 1975, 1993, 2000), Politecnico of Turin present of (Chiorino et al. 2007) and ČVUT in Prague present of (Křistek 1988).

\section{RESEARCH SIGNIFICANCE}

The investigation of creep effect in composite steelconcrete beams has been an important task for engineers since the first formulation of the mathematical model of linear viscoelasticity (Bažant 1975). The mechanic-mathematical model and design equations for describing the creep effect of composite sections are 
based on the integral equations of Volterra of second kind. The paper discusses the problem concerned with the development of computer program for the automatic computation (both numerical and graphical) of the entire set of functions that are of interest for creep analysis of composite - concrete structures, on the basis of the physical parameters characterizing the structural problem under consideration, and with reference to three prevailing creep prediction models. The paper analyzes the time dependent behaviour of composite steelconcrete beam with respect to rheological properties of concrete according to world code provisions: Eurocode2 (Comité Européen de Normalisation [CEN] 2004a, ACl209R-92 (ACl Committee 209, 2008), and GL2000 (Gardner and Lockman 2001).

\section{FUNDAMENTALS OF LINEAR VISCOELASTICITY OF AGING MATERIALS APPLIED TO CONCRETE}

Concrete is considered to comply with the linear theory of viscoelasticity for aging materials (Bažant et al. 1975, 1993, 2000), (Chiorino et al. 2007), and (Křistek 1988). Introducing the creep (compliance) function $J(t, \tau)$ and summing the responses to all uniaxial stress increments introduced at times $\tau$, the following integral relations are obtained to model the responses at time $t$ to sustained variable imposed stresses.

$$
\varepsilon_{c \sigma}(t)=\int_{t_{0}}^{t} \frac{d \sigma}{d \tau} J(t, \tau) d \tau
$$

where: $\varepsilon_{c \sigma}=\varepsilon_{c}(t)-\varepsilon_{c n}(t)=$ stress - dependent strain; $\varepsilon_{c}(t)=$ total strain at time $t ; \varepsilon_{c n}(t)=$ stress independent strain. Here the hereditary integrals must be intended as Stieltjes integrals in order to admit discontinuous stress histories $\sigma(t)$.If the law of variation of the imposed stress is considered continuous after an initial finite step, the ordinary Rieman definition of the integral applies and eqs.(1) may be written in the form:

$$
\varepsilon_{c \sigma}(t)=\sigma\left(t_{0}\right) J\left(t, t_{0}\right)+\int_{t_{0}}^{t} \frac{d \sigma}{d \tau} J(t, \tau) d \tau
$$

Equation (1) can be written in the operator form: $\varepsilon_{c \sigma}=J \sigma$, where $J$ represent the unaxial creep operators according to (Bažant 1975).

The compliance function $J(t, \tau)$ is normally separated, on the basis of some convention, into an initial strain $J(\tau+\Delta, \tau)$ with $\Delta=t-\tau$ small, which is treated as instantaneous and elastic (nominal elastic strain) introducing a corresponding elastic modulus for the concrete $E_{c}(\tau)$, and a creep strain $C(t, \tau)$, i.e:

$$
\begin{gathered}
J(\tau+\Delta, \tau) \cong J(\tau, \tau)=1 / E_{c}(\tau) ; \\
J(t, \tau)=1 / E_{c}(\tau)+C(t, \tau) ;
\end{gathered}
$$

A creep coefficient $\phi$ is normally introduced representing the ratio between the creep strain $C(\tau, t)$ and the initial strain at $t=\tau$ (e.g. in B3 model), or at a conventional age $\tau$ at loading (e.g. in CEB MC90 model, with $\tau=28$ days), i.e.:

$$
\begin{gathered}
J(t, \tau)=\frac{1}{E_{c}(\tau)}+\frac{\phi(t, \tau)}{E_{c}(\tau)} ; \\
J(t, \tau)=\frac{1}{E_{c}(\tau)}+\frac{\phi_{28}(t, \tau)}{E_{c 28}(\tau)} ;
\end{gathered}
$$

It must be noted that for structural analysis the compliance function $J(t, \tau)$ is very important. The conventional separation adopted in eq. (3) and the value of $\Delta$ in eq. (2) have no influence on the result of the analysis, except in the definition of the "initial" (nominally elastic) state of deformation or of stress due to a sudden application of actions (respectively forces or imposed deformations). Such a state is in effect by itself a matter of convention depending on the procedures in the application of the actions at $t=t_{0}$ on the structure, on the initial time $t_{0}+\Delta$ of observation of the effect and on measuring procedures.

Time-dependent properties of concrete are fully characterized by $J(t, \tau)$. For realistic forms of $J(t, \tau)$ eq. (1) cannot be integrated analytically, and numerical integration is mandatory.

In this respect, it must be considered that creep of concrete is a very complex phenomenon involving several interacting physical mechanisms at different scales of microstructure, which are influenced by many factors; physical mechanisms and modelling criteria are still being debated (Bažant, 1993, 2000). Hence, a relatively high degree of sophistication in a realistic creep prediction model is unavoidable. A further cause of complexity of creep models to be used in structural analysis is the need to provide the average creep properties of the cross section for traditional simplified one-dimensional analysis of beams and frames. Such properties are characterized by non-uniform creep and shrinkage developing within the section, due to the drying process, and are influenced by the cross section geometry and stress distribution. As a consequence, the algebraic expressions for the prediction of compliance function $J(t, \tau)$ for the average creep properties of the concrete cross section in drying conditions are inevitably rather complex (and less accurate than the constitutive law for a material point) in all the prevailing creep prediction models presented in recent literature (Bažant, 1993, 2000), and/or considered by international associations [CEB (1993), ACI (2004)]. Standard numerical procedures for the solution of integral equation of Volterra have been developed by Bažant (Jirasek\&Bažant 2002), and they have been incorporated in manuals design by (Chiorino 2010), bringing to an end a line of research, that has been investigated for more than fifty years. It has been in fact practically demonstrated that no formulation for $J(t, \tau)$ can be found that is sufficiently accurate and allows at the same time the precisely solution of the creep problem in the structures. The problem of the creep induced stress redistribution in the composite steel-concrete beams is dealt with within the theory of linear viscoelasticity for aging materials, which is normally considered appropriate for the creep analysis of structures (Bažant 1975, 1993, 2000) and (Chiorino 
$2007,2010)$. Recent progresses of the theory of linear viscoelasticity, extended to materials like concrete showing a complex creep behaviour, allow a rational interpretation of any kind of creep induced structural effects through very compact formulations on the basis of integral equations of Volterra. For this purpose, proper design aids, to be inserted in manuals of bridge practice, can be offered to designers by a numerical solution of the Volterra integral equation, performed once for ever for the above mentioned creep prediction models suggested by international civil engineering associations, or of a powerful numerical solution for the automatic immediate calculation of development of internal forces in the time $t$ from any given compliance function $\mathrm{J}\left(t, t_{0}\right)$. This paper focuses on the development of these numerical solutions and theoretically consistent procedures, and of the corresponding design aids, for the evaluation of the creep induced stress redistribution in composite steel-concrete sections and on their application to steel-concrete bridges.

\section{BASIC EQUATIONS FOR DETERMINING CREEP COEFFICIENT ACCORDING TO VARIOUS CREEP MODELS AND PROVISIONS}

\section{Eurocode 2 model}

The creep (compliance) function proposed by the 1990 CEB Model Code ("CEB-FIP"1991) is given by the relationship: $J\left(t, t_{0}\right)=\frac{1}{E_{c}\left(t_{0}\right)}+\frac{\phi\left(t, t_{0}\right)}{E_{c}}$, where $\varphi\left(t, t_{0}\right)=$ the creep coefficient; and $E_{c}\left(t_{0}\right)$ and $E_{c}=$ modulus of elasticity at the age of $t_{0}$ and 28 days, respectively[1]. The creep coefficient is evaluated with the following formula: $\phi\left(t, t_{0}\right)=\phi_{R H} \beta\left(f_{c m}\right) \beta\left(t_{0}\right) \beta_{c}\left(t-t_{0}\right) \quad$ where $\phi_{R H}=1+\frac{1-R H / 100}{0.46\left(h_{0} / 100\right)^{0.33}}$ - is a factor to allow for the effect of relative humidity on the notional creep coefficient. $R H$ is the relative humidity of the ambient environment in $\% \beta\left(f_{c m}\right)=\frac{5.3}{\left(f_{c m} / 10\right)^{0.5}}$ - is a factor to allow for the effect of concrete strength on the notional creep coefficient. $\beta\left(t_{0}\right)=\frac{1}{0.1+\left(t_{0}\right)^{0.2}}-$ is a factor to allow for the effect of concrete age at loading on the notional creep coefficient (the function is considered for continuous process).

$$
\beta(\tau)=\frac{1}{0.1+(\tau)^{0.2}} \text { is a function of aging, depending }
$$

on the age of concrete and it characterizes the process of aging. $\beta_{c}\left(t-t_{0}\right)=\left[\frac{t-t_{0}}{\beta_{H}+\left(t-t_{0}\right)}\right]^{0.3}$ is a function to describe the development of creep with time after loading. $\quad \beta_{H}=150\left[1+\left(1.2 \frac{R H}{100}\right)^{18}\right] \frac{h_{0}}{100}+250 \leq 1,500$ coefficient depending on the relative humidity $(R H$ in \%) and notional member size $\left(h_{0}\right.$ in $\left.\mathrm{mm}\right)$, where $f_{c m}=f_{c k}+8=$ the mean compressive strength of concrete at the age of 28 days (MPa); and $h_{0}=\frac{2 A_{c}}{u}=$ the notional size of member $(\mathrm{mm})\left(A_{c}=\right.$ the cross section; and $u=$ the perimeter of member in contact with the atmosphere). Constant Young's modulus is given by $E_{c}=10^{4}\left(f_{c m}\right)^{\frac{1}{3}}$. Variable Young's modulus is given by: $E_{c}(t)=\beta_{c c}^{0.5} E_{c}$, where $E_{c}=10^{4}\left(f_{c m}\right)^{\frac{1}{3}}$ and $\beta_{c c}=\exp \left[s\left(1-5.3 / t^{0.5}\right)\right]$, where $s$ $=0.25$ for normal and rapid hardening cements. So $E_{c}(t)=336190 e^{0.5\left[0.25\left(1-\frac{5.3}{\sqrt{t}}\right)\right]}, \phi_{0}=\phi_{R H} \beta\left(f_{c m}\right) \beta\left(t_{0}\right)$ is a final creep.

\section{ACl 209R-92 model}

This is an empirical model developed by (Branson and Christiason 1977), with minor modification introduced in ACl 209R-92(ACl Committee 209, 2008). The shape of the curve and ultimate value depend on several factors such as curing conditions, age of application of load, mixture proportioning, ambient temperature and humidity. Correction factors are applied to ultimate values. Since the linear function of the ultimate values is creep equation for any period, the correction factors in this procedure may be applied to short -term creep. The creep function proposed by the $\mathrm{ACl}$ 209R-92 model, that presents the total stressdependent strain by unit stress is given by the relationship: $J\left(t, t_{0}\right)=\frac{1}{E_{c m t 0}}+\frac{\phi\left(t, t_{0}\right)}{E_{c m t 0}}=\frac{1+\phi\left(t, t_{0}\right)}{E_{c m t 0}}$, where - $\phi\left(t, t_{0}\right)$ is the creep coefficient as the ratio of the creep strain to the elastic strain at the start of loading at the age $t_{0}$ (days) and $E_{c m t 0}$ is the modulus of elasticity at the time of loading $t_{0}$ ( $\mathrm{MPa}$ or psi), respectively. The creep model proposed by ACl 209R-92 has two components that determine the ultimate asymptotic value and the time development of creep. The predicted parameter is not creep strain, but creep coefficient $\phi\left(t, t_{0}\right)$, (defined as the ratio of the creep strain to the initial elastic strain). The creep coefficient is evaluated with the following formula: $\phi\left(t, t_{0}\right)=\phi_{u} \beta_{c}\left(t-t_{0}\right)$, where: $\phi\left(t, t_{0}\right)$ is the creep coefficient at the concrete age $t$ due to a load applied at the age $t_{0} ;\left(t-t_{0}\right)$ is the time since application of load; $\phi_{u}$ is the ultimate creep coefficient. For standard conditions in the absence of specific creep date for local aggregates and conditions, the average value proposed for the ultimate creep coefficient $\phi_{u}$ is equal to 2,35. For conditions 
other than standard conditions the value of the ultimate creep coefficient $\phi_{u}=2.35$ should be modified by six correction factors, depending on particular conditions: where: $\phi_{u}=2.35 \gamma_{c} ; \quad$ and: $\gamma_{c}=\gamma_{c, t 0} \gamma_{c, R H} \gamma_{c, v s} \gamma_{c, s} \gamma_{c, \psi} \gamma_{c, \alpha} ; \quad \gamma_{c, t 0}=1.25 t_{0}^{-0.118}$ corresponds to $\beta\left(t_{0}\right)$ in CEB MC90, is a function of aging, depending on the age of concrete and it characterizes the process of aging; $\gamma_{c, R H}=1.27-0.67 h$ for $h \geq 0.40$ is the ambient humidity factor, where the relative humidity $h$ is in decimal -correspond to $\phi_{R H}$ CEB MC90 ; $\gamma_{c, v s}=\frac{2}{3}\left(1+1.13 e^{\{-0.0213(V / S)\}}\right)$ (corresponds to $\beta_{H}$ in CEB MC90), where $\mathrm{V}$ is the specimen volume in $\mathrm{mm}^{3}$ and $S$ the specimen surface area in $\mathrm{mm}^{2}$, allows to consider the size of member in terms of the volumesurface ratio; $\gamma_{c, s}=0.82+0.00624 s$ is slump factor, where $s=75 \mathrm{~mm}$ is the slump of fresh concrete; $\gamma_{c, \psi}=0.88+0.0024 \psi$ is fine aggregate factor, where $\psi=40$ is the ratio of fine aggregate to total aggregate by weight expressed as percentage; $\gamma_{c, \alpha}=0.46+0.09 \alpha \geq 1$ is air content factor, where $\alpha=2$ is the air content in percentage. $\beta_{c}\left(t-t_{0}\right)=\left[\frac{\left(t-t_{0}\right)^{0.6}}{10+\left(t-t_{0}\right)^{0.6}}\right]$ - is a function to describe the development of creep with time after loading. The secant modulus of elasticity of concrete $E_{c m t 0}$ at any time $t_{0}$ of loading is given by $E_{m c t 0}=0,043 \rho_{c}{ }^{1,5} \sqrt{f_{c m t 0}} \quad \mathrm{MPa}$; where $\rho_{c}$ is the unit weight of concrete $\left(\mathrm{kg} / \mathrm{m}^{3}\right)$ and $f_{c m t 0}$ is the mean concrete compressive strength at the time of loading (MPa).The general equation for predicting compressive strength at an time $t$ is given by $f_{c m t}=\left[\frac{t}{a+b t}\right] f_{c m 28}$, where $f_{c m 28}$ is the concrete mean compressive strength of 28 days in $\mathrm{MPa} ; a$ (in days) and $b$ are constant and $t$ is the age of the concrete.

\section{Gardner\&Lockman 2000 model}

It is a modified Atlanta 97 model 1993(Gardner and Lockman 2001, which itself was influenced by CEB MC90-99. The compliance expression is based on the modulus of elasticity at 28 days, instead of the modulus of elasticity at age of loading. This model includes a term for drying before loading, which applies to both basic and drying creep. Required parameters: Age of concrete when drying starts, usually taken as the age at the end of moist curing (days); Age of concrete at loading (days); Concrete mean compressive strength at 28 days
(MPa or psi); Concrete means a compressive strength at loading (MPa or psi); Modulus of elasticity of concrete at 28 days (MPa or psi); Modulus of elasticity of concrete at loading (MPa or psi); Relative humidity expressed as a decimal; and Volume-surface ratio ( $\mathrm{mm}$ or in.); The creep (compliance) function proposed by the (Gardner and Lockkman 2001), is composed of the elastic and creep strains. The elastic strain is reciprocal of the modulus of elasticity at the age of loading $E_{c m t o}$ and the creep strain is the 28 day creep coefficient $\phi_{28}\left(t, t_{0}\right)$ divided by the modulus of elasticity at 28 days $E_{c m 28}$. The creep coefficient $\phi_{28}\left(t, t_{0}\right)$ is the ratio of the creep strain to the elastic strain due to the load applied at the age of 28 days. So: $J\left(t, t_{0}\right)=\frac{1}{E_{c m t 0}\left(t_{0}\right)}+\frac{\phi_{28}\left(t, t_{0}\right)}{E_{c m 28}}$; where: $E_{c m t 0}$ is the modulus of elasticity of concrete at the time of loading $t_{0} ; E_{c m 28}$-is the mean modulus of elasticity concrete at 28 days $(\mathrm{MPa}) ; 1 / E_{c m t 0}$ - represents the initial strain per unit stress at loading. $\phi\left(t, t_{0}\right)$ gives the ratio of the creep strain since the start of loading at the age $t_{0}$ to the elastic strain due to a constant stress applied at a concrete age of 28 days; The 28-day creep coefficient $\phi_{28}\left(t, t_{0}\right)$ calculated using the next formulae:

$$
\begin{aligned}
& \phi_{28}\left(t, t_{o}\right)=\Phi\left(t_{c}\right)\left[2 \frac{\left(t-t_{o}\right)^{0,3}}{\left(t-t_{o}\right)^{0,3}+14}+\left(\frac{7}{t_{0}}\right)^{0,5}\left(\frac{\left(t-t_{o}\right)}{\left(t-t_{o}\right)+7}\right)^{0,5}+\right. \\
& \left.+2,5\left(1-1,086 h^{2}\right)\left(\frac{\left(t-t_{o}\right)}{\left(t-t_{o}\right)+0,12(V / S)^{2}}\right)^{0,5}\right] .
\end{aligned}
$$

The creep coefficient includes three terms. The first two terms are required to calculate the basic creep, and the third term is for the drying creep. At a relative humidity of 0.96 there is only basic creep. There is no drying creep. $\Phi_{\left(t_{c}\right)}$ is the correction term for the effect of drying before loading. If $t_{o}=t_{c} ; \Phi\left(t_{c}\right)=1$; When:

$$
\begin{aligned}
t_{0}>t_{c} \\
\Phi\left(t_{c}\right)=\left[1-\left(\frac{\left(t_{0}-t_{c}\right)}{\left(t_{0}-t_{c}\right)+0,12(V / S)^{2}}\right)^{0,5}\right]^{0,5} ;
\end{aligned}
$$

$t_{o}=$ age of concrete at loading, (days); $t_{c}=$ age of concrete when drying starts at the end of moist curing, (days).

To calculate relaxation, $\Phi\left(t_{c}\right)$ remains constant at the initial value throughout the relaxation period. For creep recovery calculation, $\Phi\left(t_{c}\right)$ remains constant at the value at the age of loading. If experimental values are unavailable the modulus of elasticity $E_{c m t}$ at any time $t$ is given by : $E_{c m t}=3500+4300 \sqrt{f_{c m t}}$, where the strength development in time can be calculated from the compressive strength using the equation 
$: f_{c m t}=\beta_{e}{ }^{2} \cdot f_{c m 28}$. This equation is a modification of the CEB strength-development relationship. So $\beta_{e}=\exp \left[\frac{s}{2}\left(1-\sqrt{\frac{28}{t}}\right]\right.$; where $s=0,4$ is $\operatorname{CEB}(1993)$

style strength - development parameter and $\beta_{e}$ relates strength development to cement type. Relationship between specified and mean compressive strength of concrete can be estimated from the equation: $f_{c m 28}=1,1 f_{c}^{\prime}+5,0$. This equation is a compromise between recommended equation of $\mathrm{ACl}$ Committee 209 (1982) and ACl Committee 363 (1992). It can be noted that this equation fails to include any effects for aggregate stiffness or concrete density. Instead of making an allowance for density of the concrete, it is preferable to measure the modulus of elasticity.

Due to further justify the present model, it is desirable to clarify the differences from other models, which are presented in this paper. According to (Bažant\&Baweja 1993, 2000), many basic features of model GL are questionable on the basis of the current understanding of the mechanics and physics of concrete shrinkage and creep, and violate the guidelines published by a RILEM Committee. Some of them are as follows: disagreement with diffusion theory, the effect of age on creep according to this model is far too weak and too short-lived, the creep coefficient for the additional creep due to drying is given in this model by a curve that does not have a bounded final value, the creep recovery curve calculated according to the principle of superposition is violated by the $G L$ model (Bažant\&Baweja 2000).

\section{BASIC ASSUPTION AND MATERIAL CONSTITUTIVE RELATIONSHIP}

The hypotheses essentially based on those introduced in last studies of (Partov and Kantchev 2014) in the elastic analysis of composite steel-concrete sections with stiff (rigid) shear connectors are assumed as following:

a) Bernoulli's concerning plane strain of crosssections (Preservation of the plane cross section for the two elements considered compositely).

b) No vertical separation between parts, in other words identical vertical displacement at the slab-beam interface is assumed.

c) The connection system is distributed continuously along the axis of the beam.

d) The cross sections are free to deform (because they belong to statically determinate structures)

e) Concrete is not cracked $\sigma_{c} \leq(0.4 \div 0.5) R_{c}$.

f) For the service load analysis of these cross sections the stress levels are small and, therefore, linear elastic behaviour may be assumed for the steel beam, i.e. Hooke's law applies to steel as well as to concrete under short-time loads.

g) Moreover, for the concrete part, if the dependence of strains and stresses upon histories of water content and temperature is disregarded, with the exclusion of large strain reversals, and under normal environment conditions, the strain can be considered as a linear function of the previous stress history alone. This linearity implies the principle of superposition, which states that strain response due to stress increments applied at different times may be added.

h) In the range of service ability loads concrete behaves in a way allowing to be treated as a linear viscoelastic body. On the basis of our assumptions for the purpose of structure analysis the total strain for concrete subjected to initial loading at time $t_{0}$ with a stress $\sigma\left(t_{0}\right)$ and subjected to subsequent stress variations $\Delta \sigma\left(t_{i}\right)$ at time $t_{i}$ may be expressed as follows: $\varepsilon_{t o t}\left(t, t_{0}\right)-\varepsilon^{s h}\left(t, t_{0}\right)=\sigma\left(t_{0}\right) J\left(t, t_{0}\right)+\int_{t_{0}}^{t} \frac{d \sigma(\tau)}{d \tau} J(t, \tau) d \tau$ , where $t$ is the time elapsed from casting of concrete; $\varepsilon_{\text {tot }}\left(t, t_{0}\right)$ - total axial strain; $\varepsilon^{s h}\left(t, t_{0}\right)$ - strain due to shrinkage, i.e. an elastic strain. Then the stress-strain behaviour of concrete can be described with sufficient accuracy by the integral equations (1) by BolztmannVolterra

$\varepsilon_{c}(t)=\frac{\sigma_{c}\left(t_{0}\right)}{E_{c}\left(t_{0}\right)}\left[1+\phi\left(t-t_{0}\right)\right]+\int_{t_{0}}^{t} \frac{d \sigma_{c}(\tau)}{d \tau} \frac{1}{E_{c}(\tau)}[1+\phi(t-\tau)] d \tau$

i) According to our proposal, the influence of the development of the bending moment $M_{c, r}(t)$ in the concrete member upon the redistribution of the normal force of concrete $N_{c, r}(t)$ can be neglected.

j) For the service load analysis no slip and uplift effects occur between the steel and concrete.

k) A single theory of interaction ignoring shear lag effects is considered. Thus, shear lag phenomenon of the deck slab is considered by using the appropriate effective slab width.

\section{BASIC EQUATION OF EQUILIBRIUM}

It is known that while in steel beam, under the effect of the serviceability loads, elastic deformations can be seen in the concrete plate during the time significant inelastic deformation take place as a consequence of creep of concrete. These inelastic strains in the concrete deck cause redistribution of stress and significant increases in deformation. Let us denote both the normal forces and the bending moments in the cross-section of the plate and the girder after the loading in the time $t=0$ with $N_{c, 0}, M_{c, 0}, N_{a, 0}, M_{a, 0}$ and with $N_{c, r}(t)$, $M_{c, r}(t), N_{a, r}(t), M_{a, r}(t)$ a new group of normal forces and bending moments, arising due to creep and shrinkage of concrete (Fig.1). For a composite bridge girder with $J_{c}=\frac{A_{c}\left(n I_{c}\right) n}{A_{s} I_{s}} \leq 0.2$, according to the suggestion of (Partov and Kantchev, 2009), the equilibrium conditions in time $t$ are the following:

$$
\begin{gathered}
N(t)=0 ; \quad N_{c, r}(t)=N_{a, r}(t) ; \\
\sum M(t)=0 ; \quad M_{c, r}(t)+N_{c, r}(t) r=M_{a, r}(t) ;
\end{gathered}
$$


Due to the fact that the problem is a twice internally statically indeterminate system, the equilibrium equations ( $7 a \& 7 b)$ are insufficient to solve it. It is necessary to produce two additional equations in the sense of compatibility of deformations of both steel girder and concrete slab in time $t$ (Fig. 1).

\section{DERIVING THE FUNDAMENTAL INTEGRAL} EQUATIONS OF VOLTERRA OF SECOND KIND FOR DETERMINING $N_{c, r}(t), M_{c, r}(t), N_{a, r}(t)$ AND

\section{$M_{a, r}(t)$}

The following Volterra type linear integral equations which hold for the determination of a new group of normal forces $N_{c, r}(t), N_{a, r}(t)$ and bending moments $M_{c, r}(t), M_{a, r}(t)$, arising due to creep of concrete, are derived.

\section{Analysis according to EC 2}

Strain compatibility on the contact surfaces between the concrete and steel members of composite girder:

For constant elasticity module of concrete strain compatibility on the contact surfaces between the concrete and steel members of composite girder is:

$$
\begin{aligned}
& \varepsilon_{s h}\left(t_{0}\right) f\left(t-t_{0}\right)+\frac{N_{c, 0}}{E_{c}\left(t_{0}\right) A_{c}}\left[1+\phi_{R H} \beta\left(f_{c m}\right) \beta\left(t_{0}\right) \beta_{c}\left(t-t_{0}\right)\right]- \\
& -\frac{1}{E_{c}\left(t_{0}\right) A_{c}} \int_{t_{0}}^{t} \frac{d N_{c, r}(\tau)}{d \tau}\left[1+\phi_{R H} \beta\left(f_{c m}\right) \beta(\tau) \beta_{c}(t-\tau)\right] d \tau+ \\
& +\frac{N_{a, 0}}{E_{a} A_{a}}-\frac{1}{E_{a} A_{a}} \int_{t_{0}}^{t} \frac{d N_{a, r}(\tau)}{d \tau} d \tau=\frac{M_{a, 0}}{E_{a} I_{a}} r+r \frac{1}{E_{a} I_{a}} \int_{t_{0}}^{t} \frac{d M_{a, r}(\tau)}{d \tau} d \tau
\end{aligned}
$$

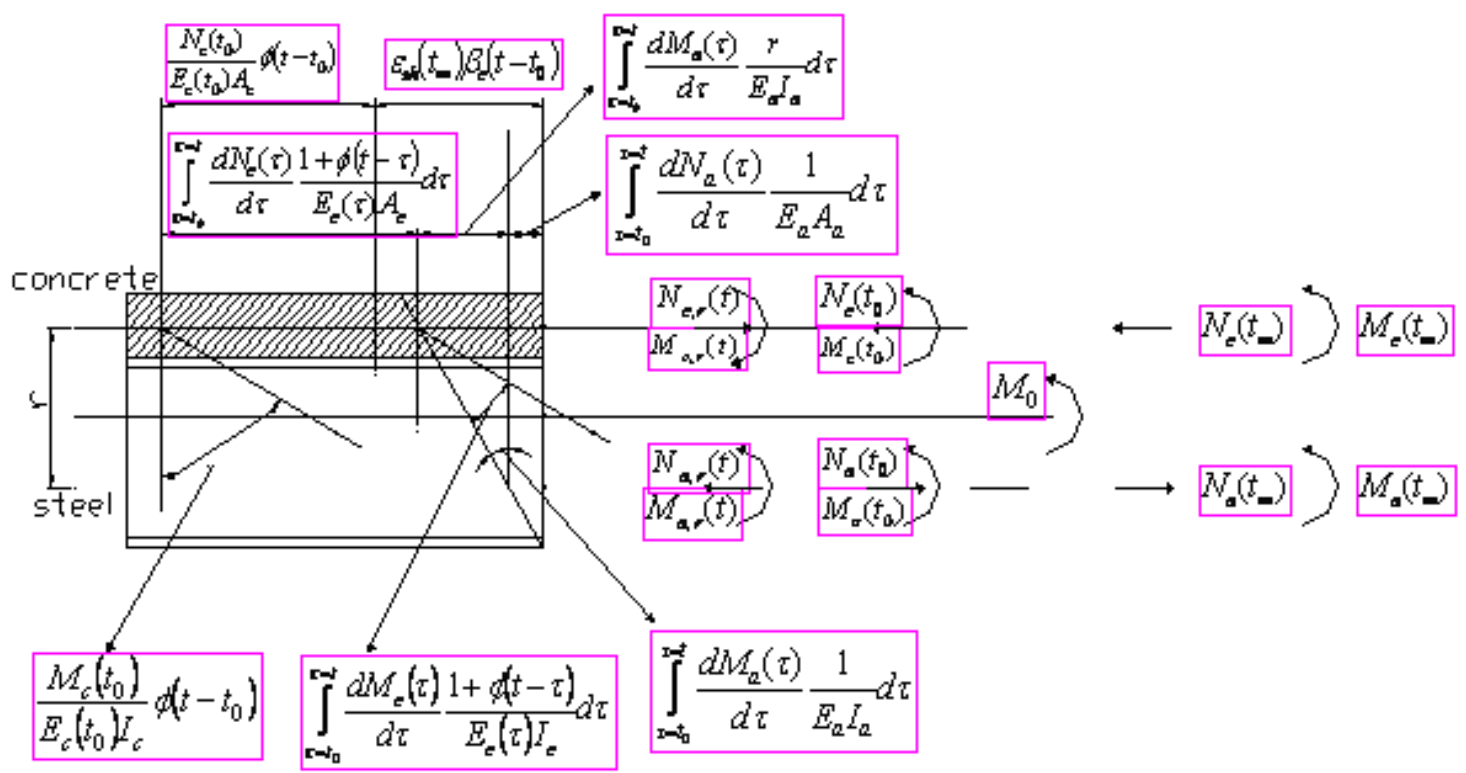

Figure 1. Mechanic-Mathematical model for deformations in cross-section, regarding creep of the concrete 


\section{Compatibility of Curvatures when $\tau=t$ is}

$$
\begin{aligned}
& \frac{M_{c, 0}}{E_{c}\left(t_{0}\right) I_{c}}\left[1+\phi_{R H} \beta\left(f_{c m}\right) \beta\left(t_{0}\right) \beta_{c}\left(t-t_{0}\right)\right]- \\
& -\frac{1}{E_{c}\left(t_{0}\right) I_{c}} \int_{t_{0}}^{t} \frac{d M_{c, r}(\tau)}{d \tau}\left[1+\phi_{R H} \beta\left(f_{c m}\right) \beta(\tau) \beta_{c}(t-\tau)\right] d \tau= \\
& =\frac{M_{a, 0}}{E_{a} I_{a}}+\frac{1}{E_{a} I_{a}} \int_{t_{0}}^{t} \frac{d M_{a, r}(\tau)}{d \tau} d \tau
\end{aligned}
$$

After integrating the two equations by parts and using the (7a and $7 b)$ for assessment of normal forces $N_{c, r}(t)$ and bending moment $M_{c, r}(t)$ two linear integral Volterra equations of the second kind are derived.

$$
\begin{aligned}
& N_{c, r}(t)=\lambda_{N} \int_{t_{0}}^{t} N_{c, r}(\tau) \frac{d}{d \tau}\left[1+\varphi \phi_{R H} \beta\left(f_{c m}\right) \beta(\tau) \beta(t-\tau)\right] d \tau+ \\
& +\lambda_{N} N_{c, 0} \phi_{R H} \beta\left(f_{c m}\right) \beta\left(t_{0}\right) \beta_{c}\left(t-t_{0}\right)+\lambda_{N} N_{s h} \beta_{c}\left(t-t_{0}\right) \\
& M_{c, r}(t)=\lambda_{M} \int_{t_{0}}^{t} M_{c, r}(\tau) \frac{d}{d \tau}\left[1+\phi_{R H} \beta\left(f_{c m}\right) \beta(\tau) \beta_{c}(t-\tau)\right] d \tau+ \\
& +\lambda_{M} M_{c, 0} \phi_{R H} \beta\left(f_{c m}\right) \beta\left(t_{0}\right) \beta_{c}\left(t-t_{0}\right)-\lambda_{M} \frac{E_{c} I_{c}}{E_{a} I_{a}} N_{c, r}(t) r
\end{aligned}
$$

where:

$$
\lambda_{N}=\left[1+\frac{E_{c} A_{c}}{E_{a} A_{a}}\left(1+\frac{A_{a} r^{2}}{I_{a}}\right)\right]^{-1} \lambda_{M}=\left[1+\frac{E_{c} I_{c}}{E_{a} I_{a}}\right]^{-1} .
$$

\section{Analysis according to ACI 209R-92}

Using the above mentioned approach, for constant elasticity module of concrete for assessment of normal forces $N_{c, r}(t)$ and bending moment $M_{c, r}(t)$ two linear integral Volterra equations of the second kind are derived.

$$
\begin{aligned}
& N_{c, r}(t)=\lambda_{N} \int_{t_{0}}^{t} N_{c, r}(\tau) \frac{d}{d \tau}\left[1+2,35 \gamma_{c 5} \beta(\tau) \beta_{c}(t-\tau)\right] d \tau+ \\
& +\lambda_{N} N_{c, 0} 2,35 \gamma_{c 5} \beta\left(t_{0}\right) \beta_{c}\left(t-t_{0}\right) \\
& M_{c, r}(t)=\lambda_{M} \int_{t_{0}}^{t} M_{c, r}(\tau) \frac{d}{d \tau}\left[1+2,35 \gamma_{c 5} \beta(\tau) \beta_{c}(t-\tau)\right] d \tau+ \\
& +\lambda_{M} M_{c, 0} 2,35 \gamma_{c} \beta\left(t_{0}\right) \beta_{c}\left(t-t_{0}\right)-\lambda_{M} \frac{E_{c} I_{c}}{E_{a} I_{a}} N_{c, r}(t) r,
\end{aligned}
$$

\section{Analysis according to Gardner\& Lockman model}

Using the above mentioned approach for constant elasticity module of concrete for assessment of normal forces $N_{c, r}(t)$ and bending moment $M_{c, r}(t)$ two linear integral Volterra equations of the second kind are derived.

$$
\begin{aligned}
& N_{c, r}(t)=\lambda_{N} \int_{t_{0}}^{t} N_{c, r}(\tau) \frac{d}{d \tau}\left[1+\Phi\left(t_{c}\right) \beta_{c}(t-\tau)\right] d \tau+ \\
& +\lambda_{N} N_{c, 0} \Phi\left(t_{c}\right) \beta_{c}\left(t-t_{0}\right) \\
& M_{c, r}(t)=\lambda_{M} \int_{t_{0}}^{t} M_{c, r}(\tau) \frac{d}{d \tau}\left[1+\Phi\left(t_{c}\right) \beta_{c}(t-\tau)\right] d \tau+ \\
& +\lambda_{M} M_{c, 0} \Phi\left(t_{c}\right) \beta_{c}\left(t-t_{0}\right)-\lambda_{M} \frac{E_{c} I_{c}}{E_{a} I_{a}} N_{c, r}(t) r
\end{aligned}
$$

\section{NUMERICAL METHOD}

The solutions of structural creep problems, resp. the aforementioned integral equations of Volterra, with realistic compliance function, such as in EC2, ACl209R92, and G\&L models for creep of concrete provisions, cannot be performed analytically and require a deep knowledge in the higher level of mathematics theory, such as integral equations of Volterra of the second kind, and its numerical solutions, using formulae for the approximation of the integrals with finite sums (quadratures) - such as: Simpson, Chebyshev, Gaus, Euler-Gregory-Macloren, rectangle and trapezoidal rules (Atkinson,1997). The last option allows a quicker solution and usually leads to acceptable approximations if the number of time steps is not too small. However, computation time is insignificant even when adopting the trapezoidal rule.

The integral equations (8-13) are weakly singular Volterra integral equation of the second kind:

$$
\begin{aligned}
& y(t)=g(t)+\lambda \int_{t_{0}}^{t} \mathrm{~K}(t, \tau) y(\tau) d \tau \\
& t \in\left[t_{0}, T\right], 0<t_{0}<T<\infty,
\end{aligned}
$$

So, in our case discontinuous kernel function $\mathrm{K}(t, \tau)$ has an infinite singularity of type $(t-\tau)^{\gamma-1}, \gamma>0$.

In order to solve (14), the idea of product integration is used by considering the special case of:

$$
\begin{aligned}
& y(t)=g(t)+\lambda \int_{t_{0}}^{t} L(t, \tau)(t-\tau)^{\gamma-1} y(\tau) d \tau \\
& t \in\left[t_{0}, T\right], 0<t_{0}<T<\infty,
\end{aligned}
$$

where the given functions $g(t)$ and $L(t, \tau)$ are sufficiently smooth which guarantee the existence and uniqueness of the solution $y(t) \in C_{\left[t_{0}, T\right]}$ (Atkinson 1997).

To solve (15) the method called product trapezoidal rule is used.

Let $n \geq 1$ be an integer and points $\left\{t_{j}=t_{0}+j h\right\}_{j=0}^{n} \in\left[t_{0}, T\right]$. Then for general $y(t) \in C_{\left[t_{0}, T\right]}$ we define 


$$
\begin{aligned}
& (L(t, \tau) y(\tau))_{n}=\frac{1}{h}\left[\left(t_{j}-\tau\right) L\left(t, t_{j-1}\right) y\left(t_{j-1}\right)+\right. \\
& \left.(L(t, \tau) y(\tau))_{n}=+\left(\tau-t_{j-1}\right) L\left(t, t_{j}\right) y\left(t_{j}\right)\right]
\end{aligned}
$$

for $t_{j-1} \leq \tau \leq t_{j} \quad t \in\left[t_{0}, T\right]$

This is piecewise linear in $\tau$ and it interpolates $L(t, \tau) y(\tau)$ at $\tau=t_{0}, \mathrm{~K}, t_{n}$. Using numerical approximation (16) the following method for solving the integral equation (15) is obtained:

$$
\begin{aligned}
& \tilde{y}_{n}\left(t_{i}\right)=g\left(t_{i}\right)+\lambda \sum_{j=0}^{i} \omega_{n, j}\left(t_{i}\right)\left[L\left(t_{i}, t_{j}\right) \tilde{y}_{n}\left(t_{j}\right)\right] \\
& \text { for } i=0,1, \mathrm{~K}, n,
\end{aligned}
$$

with weights

$$
\begin{aligned}
& \omega_{n, 0}\left(t_{i}\right)=\frac{1}{h} \int_{t_{0}}^{t_{1}}\left(t_{1}-\tau\right)\left(t_{i}-\tau\right)^{\gamma-1} d \tau \\
& \omega_{n, n}\left(t_{n}\right)=\frac{1}{h} \int_{t_{n-1}}^{t_{n}}\left(\tau-t_{n-1}\right)\left(t_{n}-\tau\right)^{\gamma-1} d \tau \\
& \omega_{n, j}\left(t_{i}\right)=\frac{1}{h} \int_{t_{j-1}}^{t_{j}}\left(\tau-t_{j-1}\right)\left(t_{i}-\tau\right)^{\gamma-1} d \tau+ \\
& +\frac{1}{h} \int_{t_{j}}^{t_{j+1}}\left(t_{j+1}-\tau\right)\left(t_{i}-\tau\right) d \tau
\end{aligned}
$$

for $i=0,1, \mathrm{~K}, n$.

Calculating analytically the weights, the approximate solution values $y_{n}\left(t_{i}\right)$ are computed from the system (17).
Theorem 1 Consider the numerical approximation defined with piecewise linear interpolation (11). Then for all sufficiently large $n$, the equation (9) is uniquely solvable and moreover if $y(t) \in C^{2}\left[t_{0}, T\right]$, then there is

$$
\left\|y-y_{n}\right\| \leq \frac{c h^{2}}{8} \max _{t_{0} \leq t, \tau \leq T}\left|\frac{\partial^{2} L(t, \tau) y(\tau)}{\partial^{2} \tau}\right| .
$$

Since $L(t,.) \in C^{2}{ }_{\left.t_{0}, T\right]}, t_{0} \leq t \leq T$ the estimate (12) is an immediate consequence of theorem 4.2.1 in Atkinson 1997.

\section{EQUIVALENT CONDITIONS FOR A COMPARISON OF MODELS}

For a comparison of the predictions of different models, equivalent conditions must be established setting the same values or equivalent parameters. Therefore, the "Guide for Modelling and Calculating Shrinkage and Creep in Harden Concrete"(ACl 209.2R08)," ACl Committee 209, 2008, American Concrete Institute, Farmington Hills, MI, 45pp was strictly followed.

\section{NUMERICAL ANALYSIS}

The method presented in the previous paragraph is now applied to a simply supported beam, subjected to a uniform load, whose cross section is shown in fig. 2.

On the base of numerous solved examples the optimal step of one day for solving the integral equations is found. The elapsed time for solving the problem for the period of twenty years (7300 days) is about up to ten minutes. For the period of about forty years (12028 12730 days - as in our case) the elapsed time increases up to forty minutes.

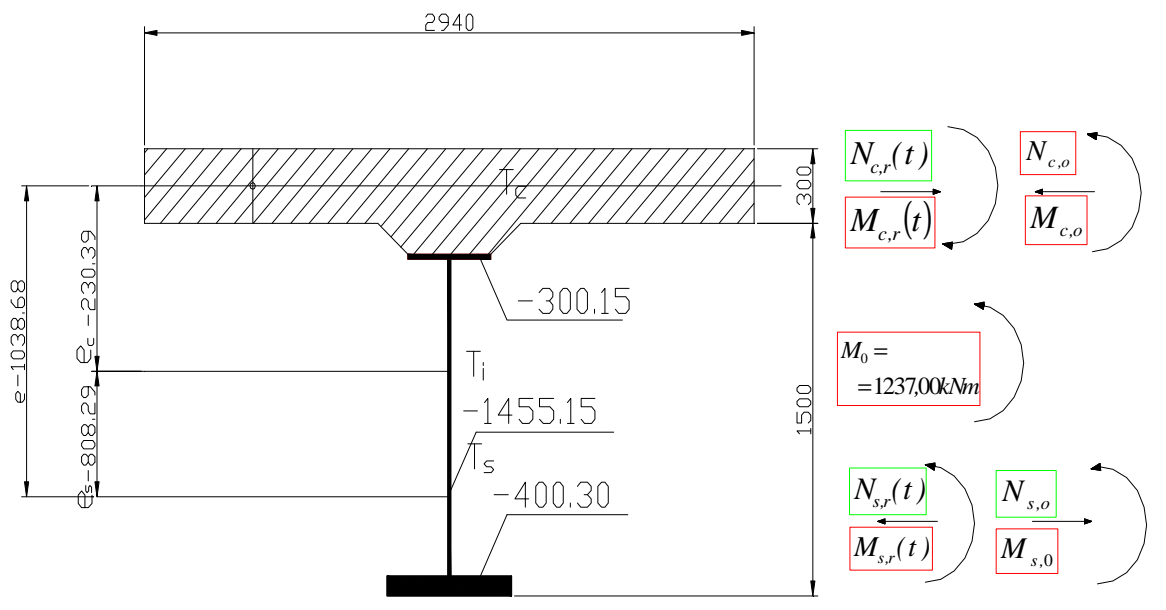

Figure 2. Composite beam with cross-section characteristic (Note: Dimensions in mm; $1 \mathrm{~mm}=0,0397 \mathrm{in}$.; $1 \mathrm{kNm}=8851 \mathrm{lbf}$.in 
The following parameters are according to EUROCODE 2 model

$E_{c}=3 \cdot 2 \cdot 10^{4} \mathrm{MPa}(4,640,000 \mathrm{psi})$,

$E_{a}=2 \cdot 1 \cdot 10^{5} \operatorname{MPa}(30,450,000 \mathrm{psi})$,

$A_{c}=8820 \mathrm{~cm}^{2}\left(1367 \mathrm{in}^{2}\right)$,

$A_{a}=383.25 \mathrm{~cm}^{2}\left(59,40 \mathrm{in}^{2}\right)$,

$n=\frac{E_{a}}{E_{c}}=6,56, I_{c}=661,500 \mathrm{~cm}^{4}\left(15,876 \mathrm{in}^{4}\right)$,

$I_{a}=1,217,963.7 \mathrm{~cm}^{4}\left(29,231 \mathrm{in}^{4}\right)$,

$r_{c}=23.039 \mathrm{~cm}(9,070 \mathrm{in})$,

$r_{a}=80.829 \mathrm{~cm}(31,823 \mathrm{in})$,

$r=103.868 \mathrm{~cm}(40,893 \mathrm{in})$,

$A_{i}=1727.762 \mathrm{~cm}^{2}\left(371,637 \mathrm{in}^{2}\right)$,

$I_{i}=4,536,360.758 \mathrm{~cm}^{4}\left(108,873 \mathrm{in}^{4}\right)$,

$M_{0}=1237 \mathrm{kNm}(10,948,687 \mathrm{lbf} . \mathrm{in})$,

$N_{c, o}=846.60 \mathrm{kN}(190,315 \mathrm{lbf})$,

$M_{c, o}=27.56 \mathrm{kNm}(243,933 \mathrm{lbf} . \mathrm{in})$,

$M_{a, o}=330.13 \mathrm{kNm}(2,921,980 \mathrm{lbf} . \mathrm{in})$,

$\lambda_{N}=\left[1+\frac{E_{c} A_{c}}{E_{a} A_{a}}\left(1+\frac{A_{a} r^{2}}{I_{a}}\right)\right]^{-1}=0.060545358$,

$\lambda_{M}=\left[1+\frac{E_{c} I_{c}}{E_{a} I_{a}}\right]^{-1}=0.922950026$

$R H=80 \%$ (humidity)

$h_{0}=2 A C / u=300 \mathrm{~mm}(11.811 \mathrm{in})$;

$\beta_{H}=150\left[1+(1.2 * 80 / 100)^{18}\right] h_{0} / 100+$

$+250=915,82<1500$;

$\beta\left(f_{c m}\right)=\left.\frac{5.3}{\left(f_{c m} / 10\right)^{0.5}}\right|_{f_{c m}=30}=3.06 ;$

$\beta\left(t_{0}\right)=\left.\frac{1}{0.1+\left(t_{0}\right)^{0.2}}\right|_{t_{0}=60}=0,4223$;

$\phi_{R H}=1+\left.\frac{1-R H / 100}{0.46 \sqrt[3]{\left(h_{0} / 100\right)}}\right|_{R H=80, h_{0}=300}=1,3014 ;$

$\phi_{0}=\phi_{R H} \beta\left(f_{c m}\right) \beta\left(t_{0}\right)=1,6817$;

$\beta_{c}(36500-60)=0,9925811$;

$\phi_{t=36500}=\phi_{0} \beta_{c}(36500-60)=1,669242$;

$R H=80 \%$ (humidity)
The following parameters are according to ACE 209R-92 model

$E_{c}=2.8178 .10^{4} \operatorname{MPa}(4,85,810 \mathrm{psi})$,

$E_{a}=2 \cdot 1 \cdot 10^{5} \mathrm{MPa}(30,450,000 \mathrm{psi})$,

$A_{c}=8820 \mathrm{~cm}^{2}\left(1367 \mathrm{in}^{2}\right)$,

$A_{a}=383.25 \mathrm{~cm}^{2}\left(59.40 \mathrm{in}^{2}\right)$,

$n=\frac{E_{a}}{E_{c}}=7,452$,

$I_{c}=661,500 \mathrm{~cm}^{4}\left(15,876 \mathrm{in}^{4}\right)$,

$I_{a}=1,217,963.7 \mathrm{~cm}^{4}\left(29,231 \mathrm{in}^{4}\right)$,

$r_{c}=25.407 \mathrm{~cm}(10.002 \mathrm{in})$,

$r_{a}=78.463 \mathrm{~cm}$ (30.891in),

$r=103.870 \mathrm{~cm}(40.893 \mathrm{in})$,

$A_{i}=1566.82 \mathrm{~cm}^{2}\left(237.37 \mathrm{in}^{2}\right)$,

$I_{i}=4,420,140.76 \mathrm{~cm}^{4}\left(106,084 \mathrm{in}^{4}\right)$,

$M_{0}=1237 \mathrm{kNm}(10,948,687 \mathrm{lbf} . \mathrm{in})$,

$N_{c, o}=837.286 k N(188,222 l b f)$,

$M_{c, o}=24.716 \mathrm{kNm}(218,802 \mathrm{lbfin})$

$M_{a, o}=338.05 \mathrm{kNm}(2,992,080 \mathrm{lbf} . \mathrm{in})$,

$\lambda_{N}=\left[1+\frac{E_{c} A_{c}}{E_{a} A_{a}}\left(1+\frac{A_{a} r^{2}}{I_{a}}\right)\right]^{-1}=0.068220902$,

$\lambda_{M}=\left[1+\frac{E_{c} I_{c}}{E_{a} I_{a}}\right]=0.93155$

$\gamma_{c, t 0}=1.25 t_{0}^{-0.118}$ corresponds to $\beta\left(t_{0}\right)=0,61684$ for $\mathrm{t}=60$ days;

$\gamma_{c, R H}=1.27-0.67 h$ for $h=0,80=0,734$;

$\gamma_{c, v s}=\frac{2}{3}\left(1+1.13 e^{\{-0.0213(V / S)\}}\right)=0,6975$,

where $\mathrm{V} / \mathrm{S}=150$;

$\gamma_{c, s}=0.82+0.00624 s=1,018$

where $s=75 \mathrm{~mm}(2.95275 \mathrm{in})$;

$\gamma_{c, \psi}=0.88+0.0024 \psi=0,976$; where $\psi=40$;

$\gamma_{c, \alpha}=0.46+0.09 \alpha \geq 1$; is air content factor, where;

$\alpha=2, \gamma_{c, \alpha}=1 ; \beta_{c}(36500-60)=0,982004$.

$R H=80 \%$ (humidity) 
$E_{c}=2.8014 .10^{4} \mathrm{MPa}(4,060,590 \mathrm{psi})$,

$E_{a}=2 \cdot 1 \cdot 10^{5} \operatorname{MPa}(30,450,000 \mathrm{psi})$,

$A_{c}=8820 \mathrm{~cm}^{2}\left(1367 \mathrm{in}^{2}\right)$,

$A_{a}=383.25 \mathrm{~cm}^{2}\left(59.40 \mathrm{in}^{2}\right)$,

$n=\frac{E_{a}}{E_{c}}=7,496$

$I_{c}=661,500 \mathrm{~cm}^{4}\left(15,876 \mathrm{in}^{4}\right)$,

$I_{a}=1,217,963.7 \mathrm{~cm}^{4}\left(29,231 \mathrm{in}^{4}\right)$,

$r_{c}=25.50 \mathrm{~cm}(10.039 \mathrm{in})$,

$r_{a}=78.37 \mathrm{~cm}$ (30.854in),

$r=103.870 \mathrm{~cm}(40.893 \mathrm{in})$,

$A_{i}=1560.82 \mathrm{~cm}^{2}\left(236.464 \mathrm{in}^{2}\right)$,

$I_{i}=4,415,813.859 \mathrm{~cm}^{4}\left(105,979 \mathrm{in}^{4}\right)$,

$M_{0}=1237 \mathrm{kNm}(10,948,687 \mathrm{lbf} . \mathrm{in})$,

$N_{c, o}=840,50 k N(188,944 l b f)$,

$M_{c, o}=24,7206 \mathrm{kNm}(218,802 \mathrm{lbf} . \mathrm{in})$;

$M_{a, o}=338.386 \mathrm{kNm}(2,995,054 \mathrm{lbf} . \mathrm{in})$,

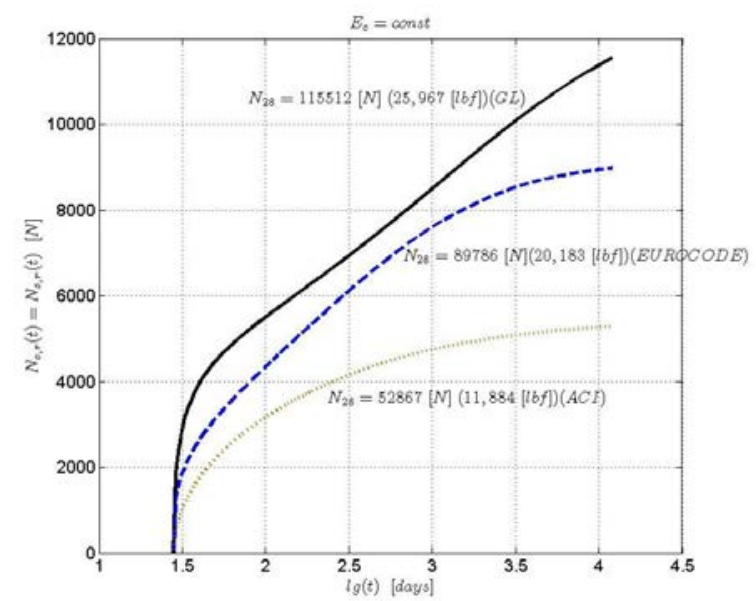

Figure 3. Normal forces $N_{c, r}(t)=N_{a, r}(t)$ in time $t=12028$ days $\left(t_{0}=28\right)$. (Note: $1 \mathrm{~N}=0.2248 \mathrm{lbf}$. $)$

$$
\begin{aligned}
& \lambda_{N}=\left[1+\frac{E_{c} A_{c}}{E_{a} A_{a}}\left(1+\frac{A_{a} r^{2}}{I_{a}}\right)\right]^{-1}=0,068593645, \\
& \lambda_{M}=\left[1+\frac{E_{c} I_{c}}{E_{a} I_{a}}\right]^{-1}=0,931921295 \\
& R H=80 \% \text { (humidity) } .
\end{aligned}
$$

\section{COMPARISONS OF THE RESULTS OBTAINED FROM DIFFERENT MODELS}

When looking at the figures from 3 to 26 the difference between the results obtain according the world standards: EC2, ACl209-R2 and G/L2000 for evaluation of creep of concrete can be seen.

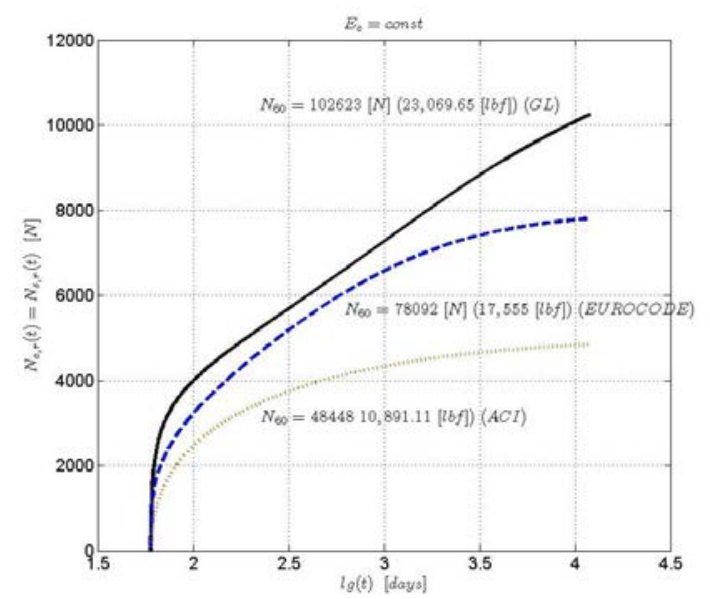

Figure 4. Normal forces $N_{c, r}(t)=N_{a, r}(t)$ in time $t=12060$ days $\left(t_{0}=60\right) .($ Note: $1 N=0.2248 \mathrm{lbf}$. $)$ 


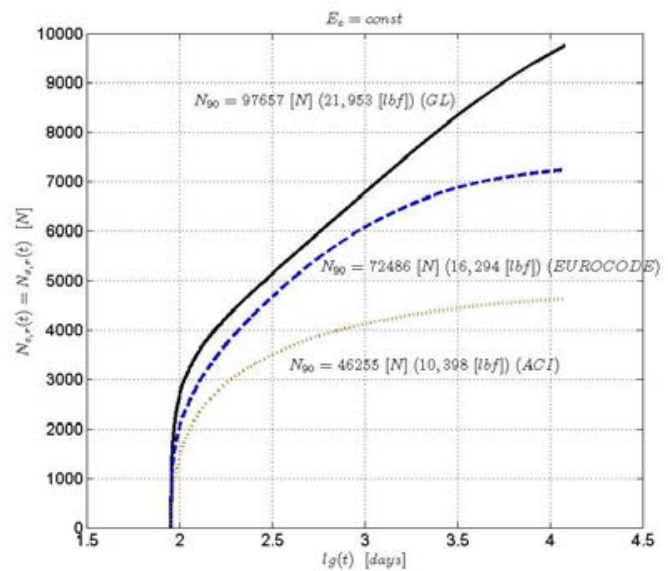

Figure 5. Normal forces $N_{c, r}(t)=N_{a, r}(t)$ in time $t=12090$ days $\left(t_{0}=90\right)$. ( Note: $1 N=0.2248$ lbf $)$

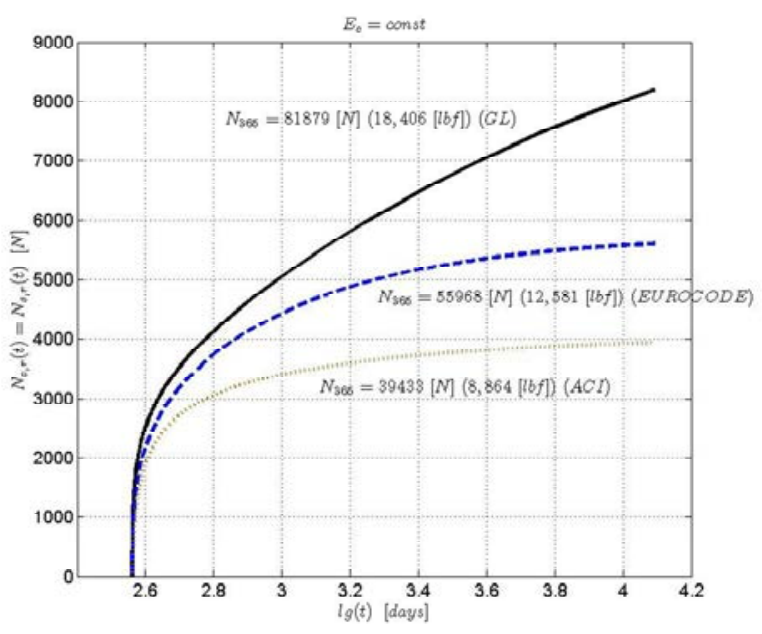

Figure 7. Normal forces $N_{c, r}(t)=N_{a, r}(t)$ in time $t=12365$ days $\left(t_{0}=365\right)$. (Note: $\left.1 N=0.2248 \mathrm{lbf}\right)$

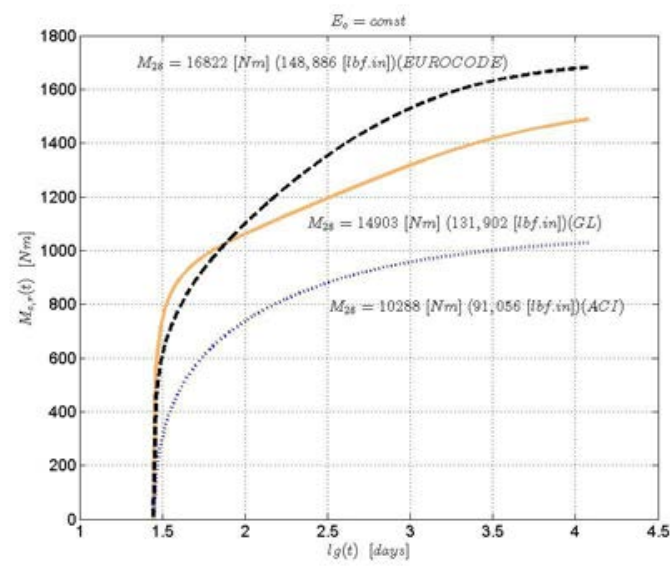

Figure 9. Bending moments $M_{c, r}(t)$ in time $t=12028$ days $\left(t_{0}=28\right)$.(Note: $1 \mathrm{Nm}=8.8507$ lbfin. $)$

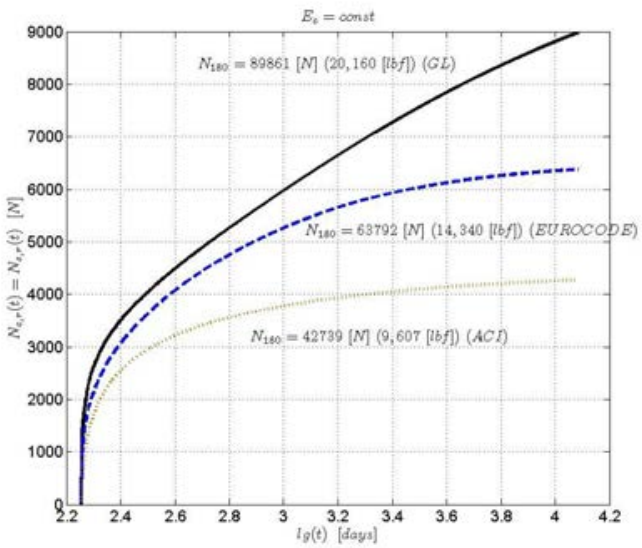

Figure 6. Normal forces $N_{c, r}(t)=N_{a, r}(t)$ in time $t=12180$ days $\left(t_{0}=180\right)$. ( Note: $\left.1 N=0.2248 \mathrm{lbf}\right)$

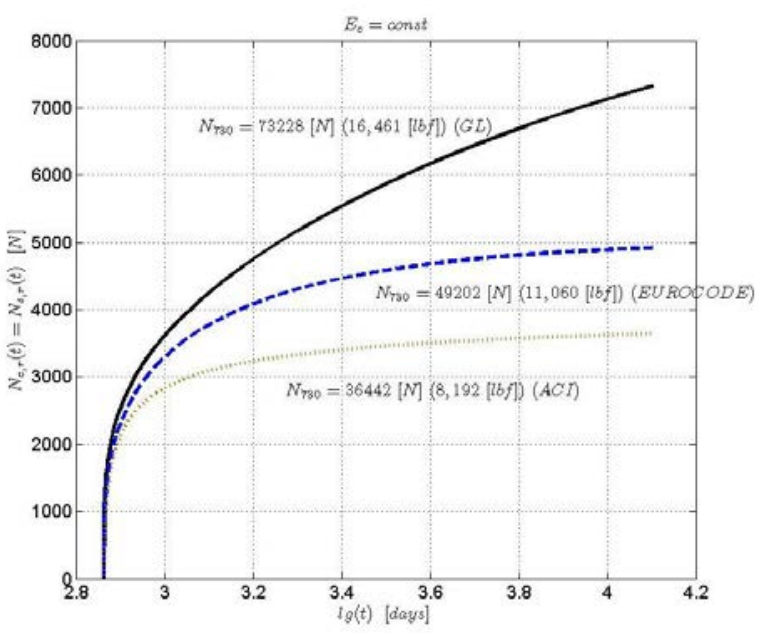

Figure 8. Normal forces $N_{c, r}(t)=N_{a, r}(t)$ in time $t=12730$ days $\left(t_{0}=730\right)$. (Note: $\left.1 N=0.2248 \mathrm{lbf}\right)$

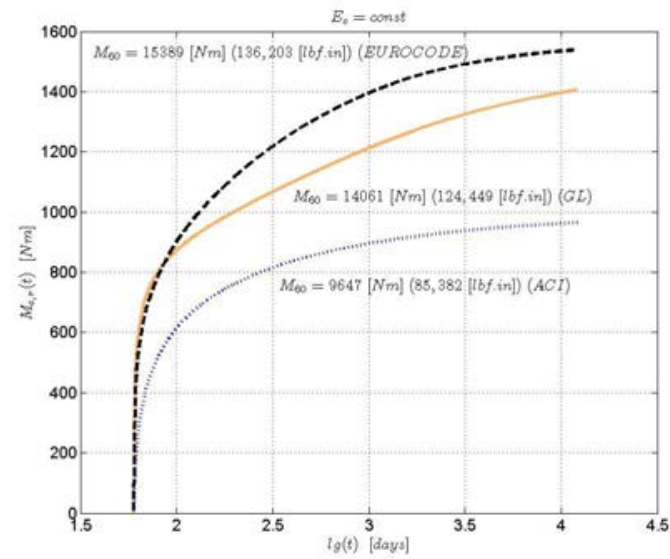

Figure 10. Bending moments $M_{c, r}(t)$ in time $t=12060$ days $\left(t_{0}=60\right)$. (Note:1 Nm=8.8507lbfin.) 


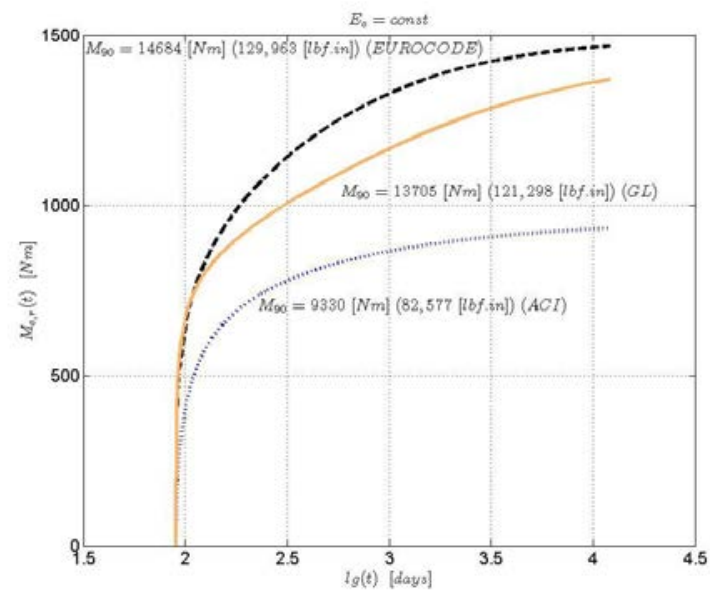

Figure 11. Bending moments $M_{c, r}(t)$ in time $t=12090$ days $\left(t_{0}=90\right)$. (1 $\mathrm{Nm}=8.8507 \mathrm{lbf}$.in. $)$

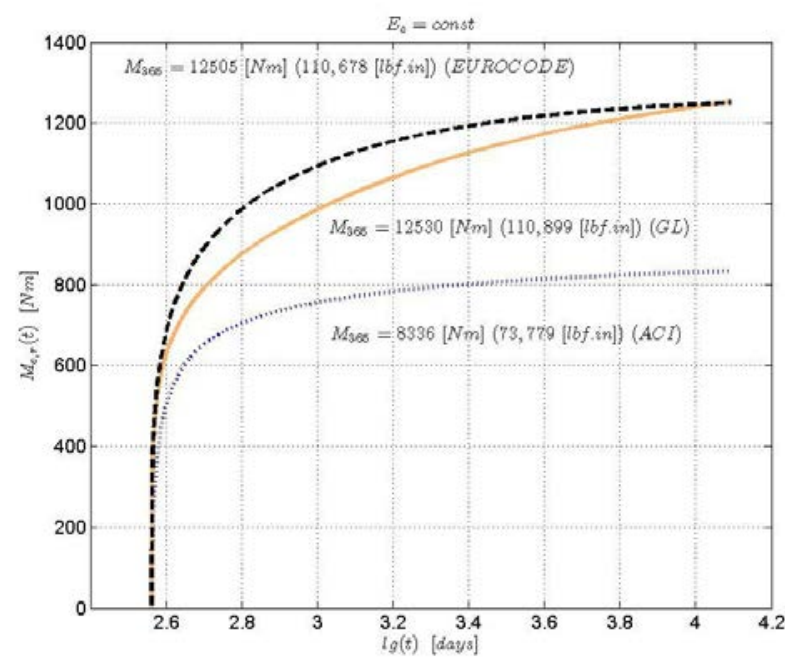

Figure 13. Bending moments $M_{c, r}(t)$ in time $t=12365$ days $\left(t_{0}=365\right)$.(Note: $1 \mathrm{Nm}=8.8507$ lbf.in.)

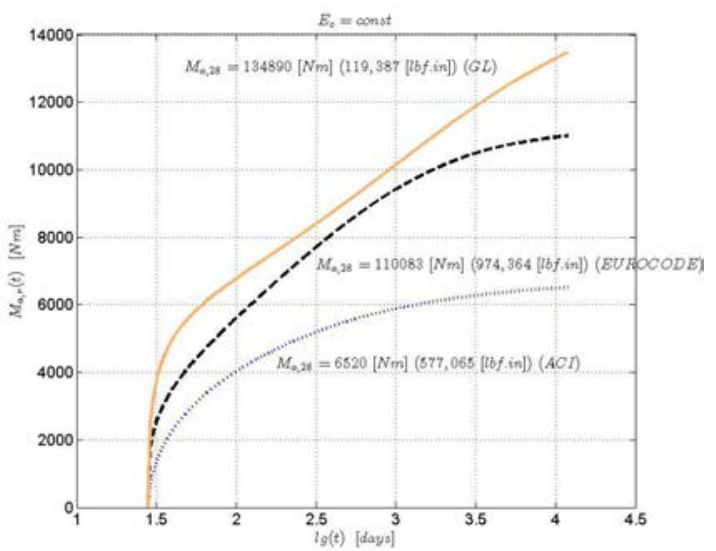

Figure 15. Bending moments $M_{a, r}(t)$ in time $t=12028$ days $\left(t_{0}=28\right)$.( Note: $1 \mathrm{Nm}=8.8507 \mathrm{lbf}$.in. $)$

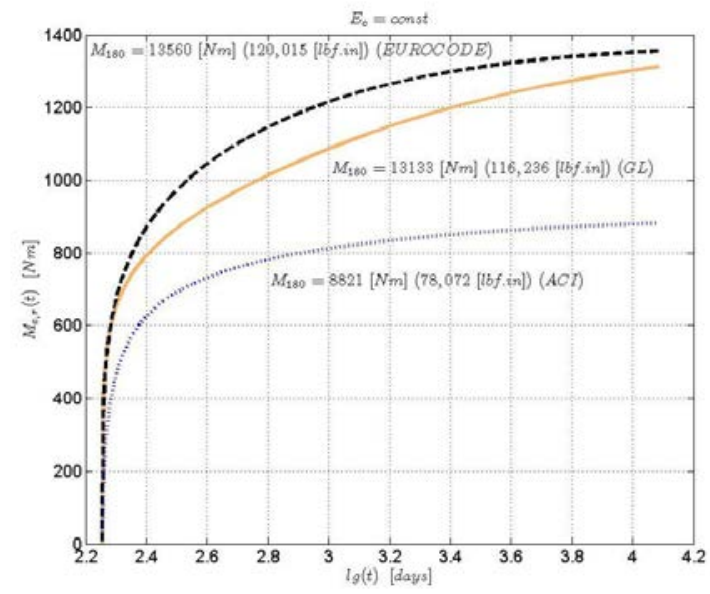

Figure 12. Bending moments $M_{c, r}(t)$ in time $t=12180$ days $\left(t_{0}=180\right)$. ( $1 \mathrm{Nm}=8.8507 \mathrm{lbf}$.in. $)$

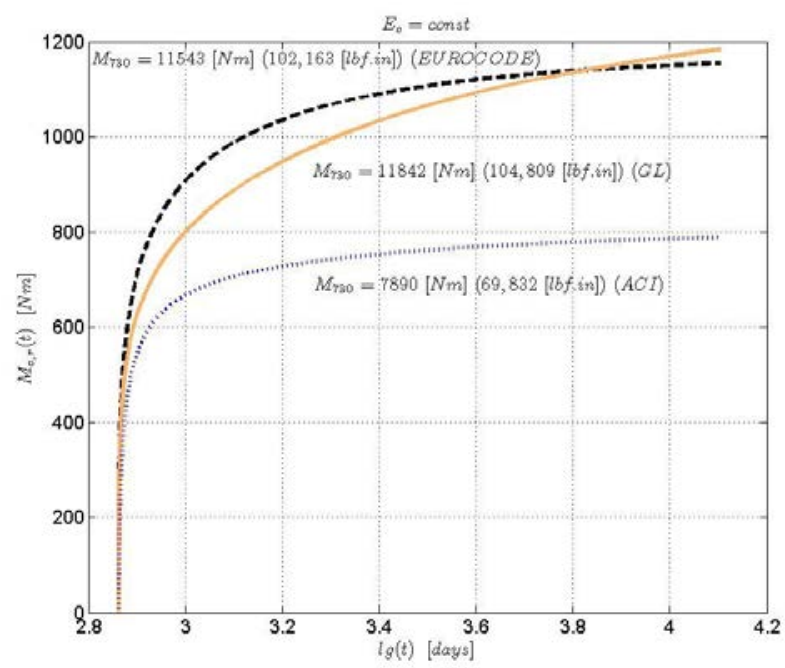

Figure 14. Bending moments $M_{c, r}(t)$ in time $t=12730$ days $\left(t_{0}=730\right)$. (Note: $1 \mathrm{Nm}=8.8507$ bf.in. $)$

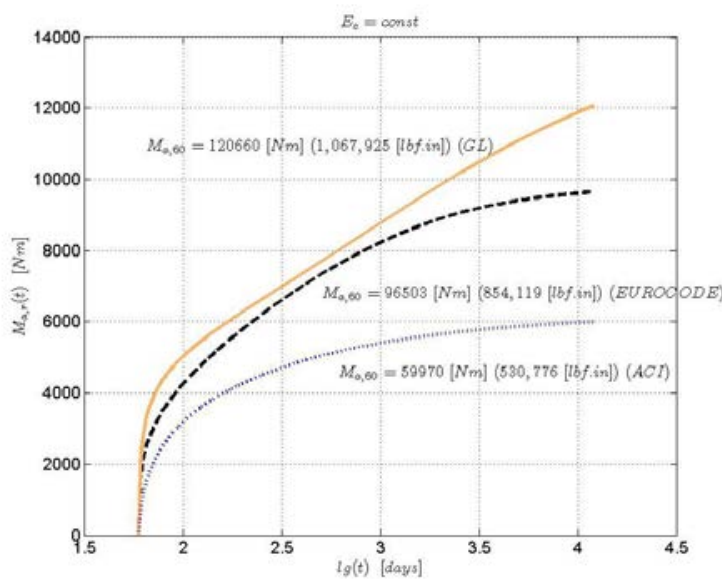

Figure 16. Bending moments $M_{a, r}(t)$ in time $t=12060$ days $\left(t_{0}=60\right)$. (Note: $1 \mathrm{Nm}=8.8507$ lbf.in. $)$ 


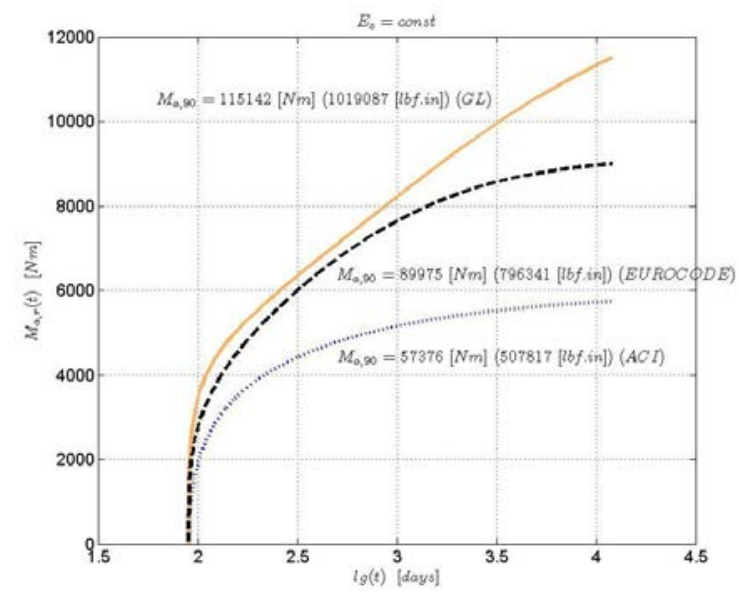

Figure 17. Bending moments $M_{a, r}(t)$ in time $t=12090$ days $\left(t_{0}=90\right)$.(Note: $1 \mathrm{Nm}=8.8507$ lbf.in. $)$

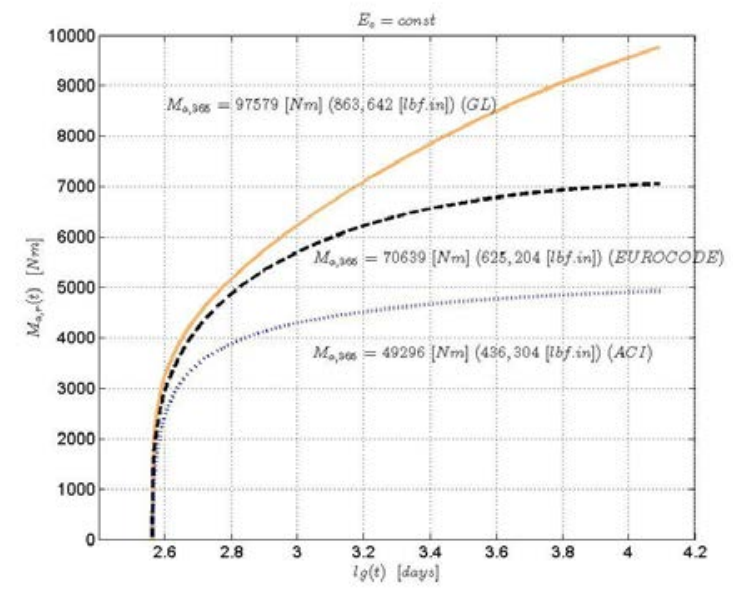

Figure 19. Bending moments $M_{a, r}(t)$ in time $t=12365$ days $\left(t_{0}=365\right)$.(Note: 1 m=8.8507lbf.in. $)$

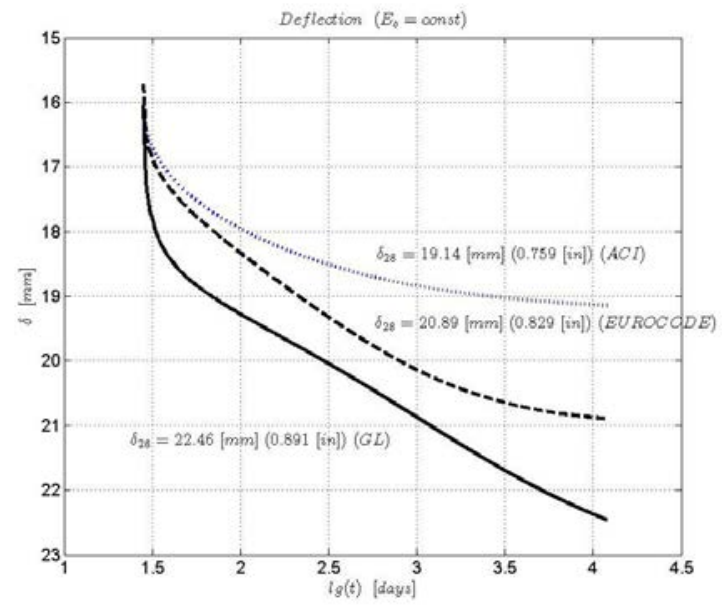

Figure 21. Deflection of steel girder (composite steelconcrete) $\delta(t)$ in time $t=12028$ days $\left(t_{0}=28\right)$ (Note:1 $\mathrm{mm}=0,0397 \mathrm{in}$ ).

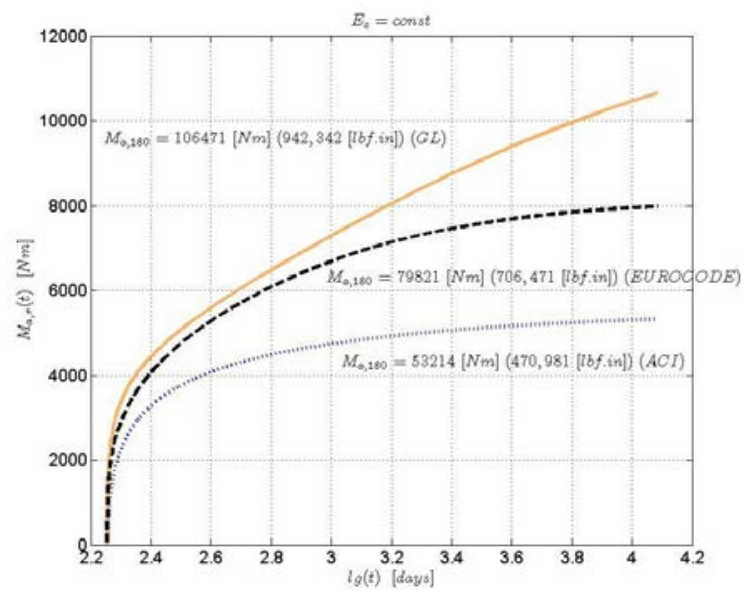

Figure 18. Bending moments $M_{a, r}(t)$ in time $t=12180$ days $\left(t_{0}=180\right)$.(Note: $1 \mathrm{Nm}=8.8507$ bf.in.)

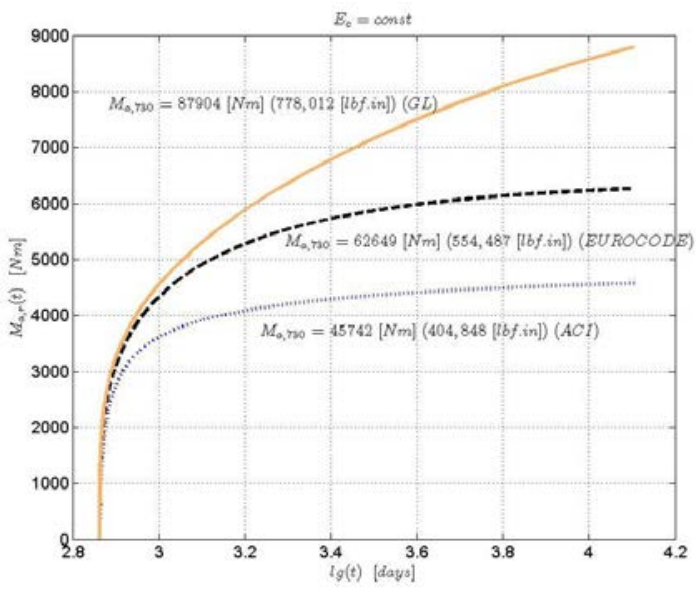

Figure 20. Bending moments $M_{a, r}(t)$ in time $t=12730$ days $\left(t_{0}=730\right)$. Note: $1 \mathrm{Nm}=8.8507$ Ibf.in.)

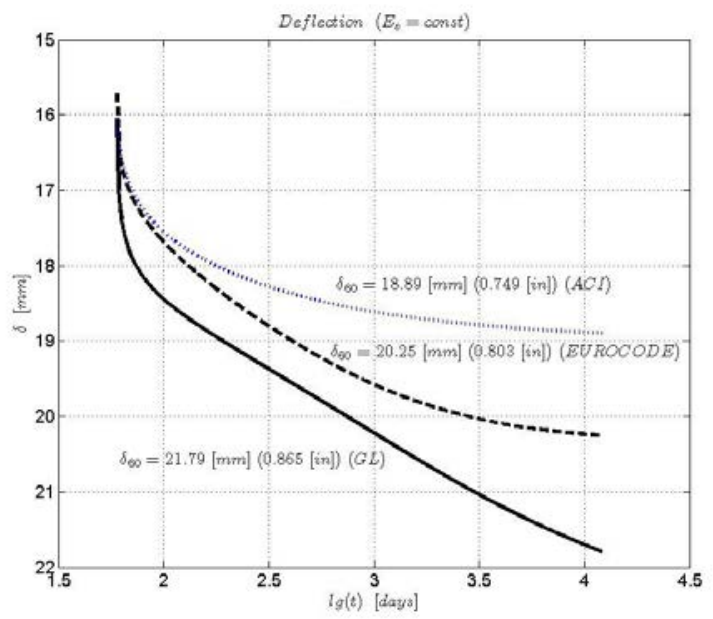

Figure 22. Deflection of steel girder (composite steelconcrete) $\delta(t)$ in time $t=12060$ days $\left(t_{0}=60\right)$ (Note:1 $\mathrm{mm}=0,0397 \mathrm{in}$ ). 


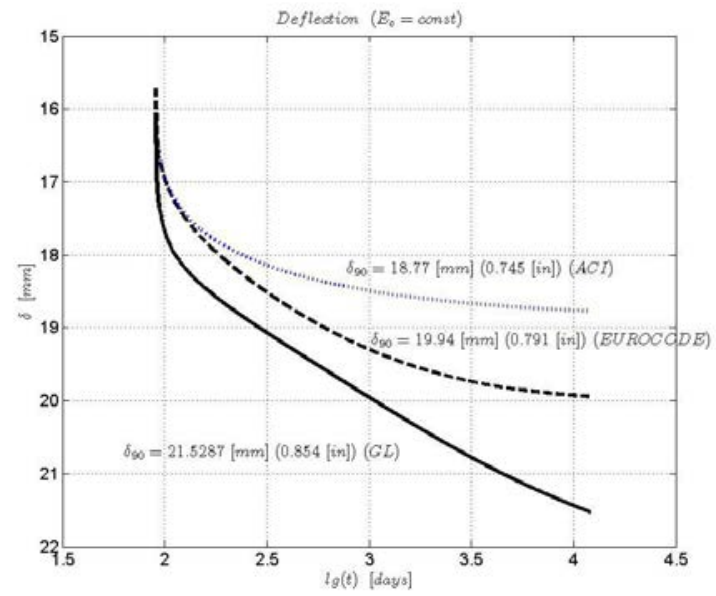

Figure 23. Deflection of steel girder (composite steelconcrete) $\delta(t)$ in time $t=12090$ days $\left(t_{0}=90\right)$

(Note:1 $\mathrm{mm}=0,0397 \mathrm{in}$ ).

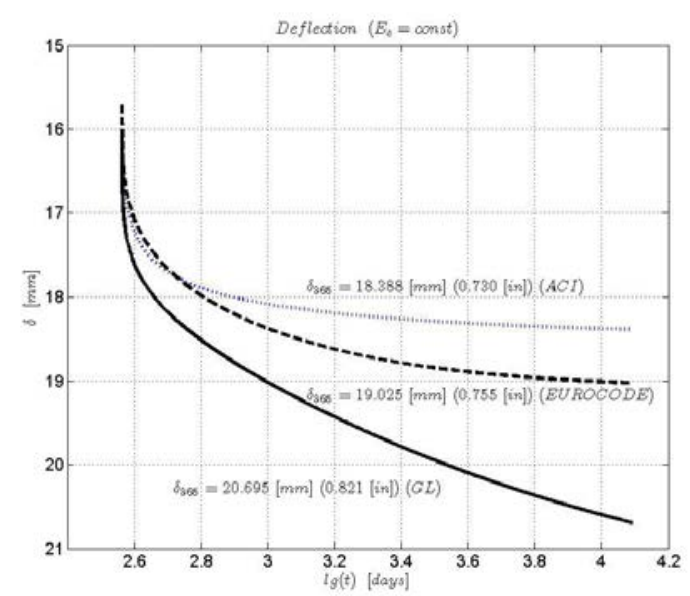

Figure 25. Deflection of steel girder (composite steelconcrete) $\delta(t)$ in time $t=12365$ days

$$
\left.\left(t_{0}=365\right) \text { (Note:1 } \mathrm{mm}=0,0397 \mathrm{in}\right) \text {. }
$$

\section{ANALYSIS OF THE RESULTS OBTAINED FROM \\ DIFFERENT MODELS}

Although the reliability of creep prediction models must be evaluated with respect to their agreement with the available experimental results essentially concerning the compliance function $J(t, \tau)$, a comparison between the predictions of different models is not devoid of interest. In fact, it has been observed (Chiorino, 2010) that in spite of good ratings-depending on the adopted statistical criteria and indicators attributed in the recent literature (Bažant, 2000) to all three considered models with regard to their agreement with the data bank, considerable difference can be observed between the predictions of different models. These differences concern both the shapes of the families of curves, and their long-term values, for all the basic functions. In fact, the influence of both long elapsed times $t=12028$ (12730)days, (e.g. for time ranges of the order

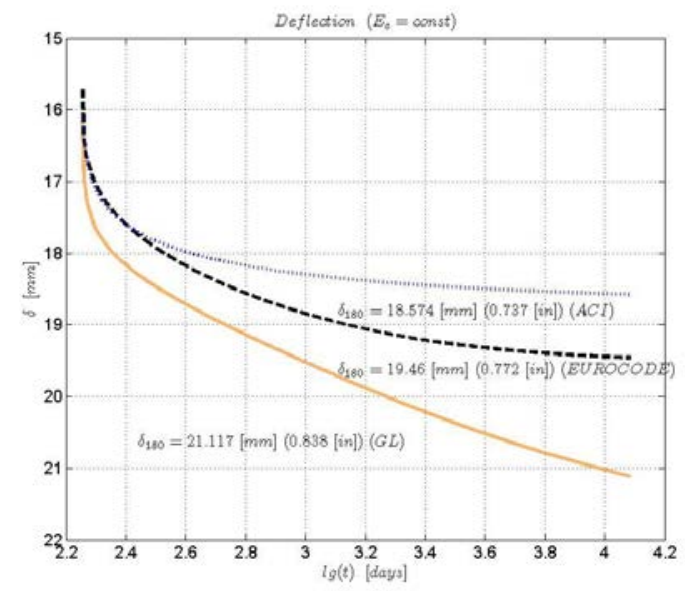

Figure 24. Deflection of steel girder (composite steelconcrete) $\delta(t)$ in time $t=12180$ days $\left(t_{0}=180\right)$ (Note:1 $\mathrm{mm}=0,0397 \mathrm{in}$ ).

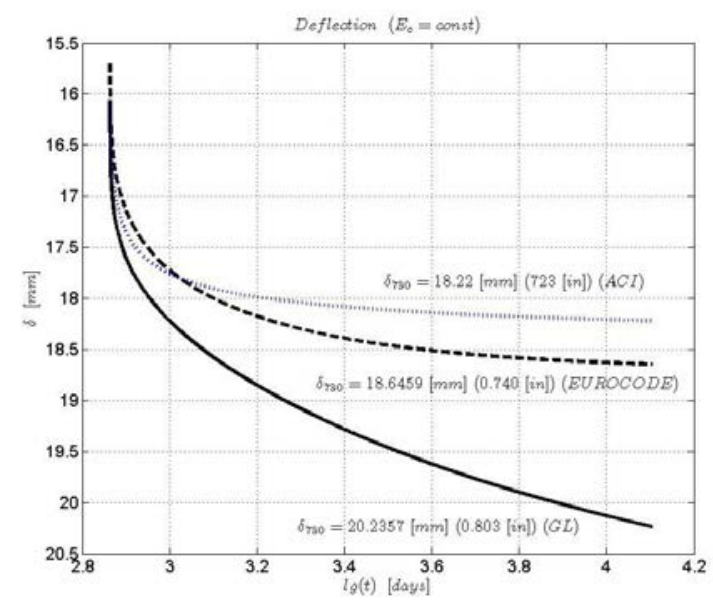

Figure 26. Deflection of steel girder (composite steel-concrete) $\delta(t)$ in time $t=12730$ days

$$
\left(t_{0}=730\right) \text { (Note:1 } \mathrm{mm}=0,0397 \mathrm{in} \text { ). }
$$

of magnitude of the service life of a structure, that largely exceed the extension of any experimental collection of date), and of almost the entire range of ages $t_{0}=28(730)$ days at the loading, is evaluated in significantly different ways by all three type of models. This can be clearly observed in the set of Figures from 3 to 26. These differences and their impact on design strategies as well as on formulation of code provisions, will be discussed in the future paper.

\section{CONCLUSIONS}

The general approach of creep analysis of composite structures based on the linear theory of viscoelasticity and on the extended use of the integral equations of Volterra of the second kind leads to precisely and theoretically correct solutions for steelconcrete composite beams with rigid shear connectors. 
In this perspective the paper has presented a powerful design tool, conceived for researches and designers, consisting of a software application for a quick automatic calculation of three basic principle creep models presently considered by international civil engineering societies. For a good accuracy of the time values, the numerical results are presented on logarithmic time scales. The choice of the length of time step of the proposed numerical algorithm is based on numerous numerical experiments with different steps (seven, three and one days). Therefore, it can be concluded that good results can be achieved from practical point of view with one day step. For our purpose we consider a period of about 33-35 years.

Our mathematical model was derived using a Stieltjes hereditary integral, which represents time loading history. It would be very interesting to investigate models with short time steps for early ages which are increased afterwards. A numerical method for timedependent analysis of composite steel-concrete sections, according to the three following models has been considered: CEB MC 90, ACl209R-92 and G/L2000. Using MATLAB code a numerical algorithm was developed and subsequently applied to a simple supported beam. These numerical procedures, suited to a PC, are employed to better understand the influence of the creep of the concrete in time-dependent behaviour of composite section. The computer program has been designed for easy use and to allow control on all the parameters involved by prediction models. It has a powerful graphic module for handling and printing charts. To allow a large distribution of this design, web pages will be created in future with the aim of developing further automatic tools devoted to the creep structural analysis of composite beams. From this web page the software can be easily downloaded.

For the service load analysis, the proposed numerical method makes it possible to follow with great precision the migration of stresses from the concrete slab to the steel beam, which occurs gradually during the time as a result of the creep of the concrete.

The parametric analysis results are characterized by the following effects:

- the state of stress in the concrete slab depends on the age of the concrete at loading time $t_{0}$;

- the stress in the top flange of the steel section increases strongly with time;

- the stress in the bottom flange undergoes small variations:

- the stress increases more for young concrete and little for old one.

From Figures from 3 to 26 it can be clearly seen that according to the proposed method according to GL2000, the forces $N_{c, r}, N_{a, r}$ and $M_{a, r}$ are much greater (between $25 \%-30 \%$ ) than the same ones in the CEB MC90-99 method. It reminds the differences obtained from the results, when solving the same task using the methods based on the theory of viscoelastic body and the theory of aging of Dischinger or modified theory of aging of Rüsch-Jungwirth. Then, we explained these facts through the assumptions of the viscoelastic body theory. According to this theory, which takes into account the delayed elastic strain developing in constrained conditions, it leads to appearance of recovery of stresses. They themselves decrease the relaxation of stresses in concrete of composite beams. That is why this fact leads to lower $N_{c, r}$ and respectively $M_{a, r}$. Therefore, according to the theory of viscoelastic body there is less stress in the steel beam, which leads to the more economic design of composite beam. To our opinion neglecting the "reversal of the creep recovery curves obtained from the GL2000 model according to the principle of superposition" denoted from Bažant in (Bažant and Baweja 2000), can be the reason for significant differences between the results obtained with the GL2000 and CEB MC90-99 methods. It means, that in the light of theory of viscoelastic body, the relaxation process in the concrete plate will be essentially greater compared with the results when the creep recovery is taken into account correctly according to CEB FIP model. (ENV 1992-I-I: 1991, ENV 1994-I-I: 1994). It is observed from figure 3-26 that $A C l 209$ code provisions in comparison with CEB FIB model code1990 underestimate, to our opinion, the influence of creep on time dependent behaviour of composite steelconcrete beams.

According to our results based on numerous practical examples it can be stated that about $90-92 \%$ of the maximum values of the stressed in concrete or steel in time $t_{\infty}$ are reached after about three years. Besides that $98 \%$ are reached after about twenty years in comparison with the period of hundred years obtained by the EMM Method (Partov and Kantchev 2014).

The results between internal forces obtained by numerical methods according to GL2000 model, ACI 209 code and CEB MC90-99 provision are incomparable with each other. It is observed from figure 3-24 that GL2000 model in comparison with CEB MC90-99 provision overestimate, to our opinion, the influence of creep on time dependent behaviour of composite steel-concrete beams. Finally, the creep effect must be carefully evaluated in order to fully understand the behaviour of the structure.

In this paper it is made an attempt to analyze the time dependent behaviour of composite steel-concrete beam with respect to rheological properties of concrete according to world code provisions GL2000, ACI209-R2 and CEB MC 90-99. All three methods lead to deferent results in practical point of view.

The most important conclusion of our investigation is that considering the creep effect, using the integral equations $(8,9), \quad(10,11)$ and $(12,13)$ a universal numerical method has been elaborated for statically determinate bridge composite plate girder according to CEB MC 90-99, ACI 209R-92 and GL2000 models. This method allows the use of a perfect linear theory of concrete creep i. e. the theory of the viscoelastic body of Boltzman-Volttera-Maslov-Arutyunyan-Trost- Bažant.

The age-adjusted effective method (AAMM) (Jirasek and Bažant 2002) and effective modulus method (EMM) mentioned above will be used in our future works as reference approximate method for comparison with our numerical solutions. Besides CEB MC90-99, ACI 209 2R-08 and GL2000 prediction models, also model Bažant - Baweja(B3), (Jirasek\&Bažant 2002) will be considered in the examples in future paper. 


\section{ACKNOWLEDGEMENT}

This article is dedicated to the scientific heritage of the great Italian mathematician Vito Volterra (18601940).

\section{REFERENCES}

[1] ACl Committee 209, 2008, "Guide for Modelling and Calculating Shrinkage and Creep in Harden Concrete"(ACl 209.2R-08)," American Concrete Institute, Farmington Hills, Ml, 45pp.

[2] Atkinson, E. K.,1997, The Numerical Solution of Integral Equations of the Second Kind, Cambridge University Press, Cambridge, UK, 572 pp.

[3] Bažant Z. P., 1975, "Theory of Creep and Shrinkage in Concrete Structures: A Précis of Recent Developments", Mechanics Today, Vol.2, Pergamon Press, New York, 1975, pp. 1-93.

[4] Bažant, Z. P.; Xi, Y. P.; Baweja, S., and Carol, I., 1993, "Preliminary guidelines and recommendations for characterizing creep and shrinkage in structural design codes", Proceedings. of the $5^{\text {th }}$ International RILEM Symposium on Creep and Shrinkage of Concrete ( Barcelona), Z. P.Bažant and I. Carol eds., E\&FN Spon, London, UK, pp.805-829.

[5] Bažant, Z. P. and Baweja, S., 2000, "Creep and Shrinkage Prediction Model for Analysis and Design of Concrete Structures: Model B3", Adam Nevile Simposium: Creep and Shrinkage Structural design Effects, SP-194, A. AlManasereer, ed., American Concrete Institute, Farmington Hills, Ml, pp.1-84.

[6] Bažant, Z. P., 2000, "Criteria for Rational Prediction of Creep and Shrinkage of Concrete", Adam Neville Symposium: Creep and Shrinkage - Structural Design Effects, SP-194, A. Al-Manaseer ed., American Concrete Institute, Farmington Hills, MI, pp. 237-260.

[7] Branson, D. E., 1977, Deformation of Concrete Structures, McGraw Hill Book Co., New York, 546 pp.

[8] Chiorino, M., Sassone, M., Bigaran, D. and Casalegno, C., 2007, "Effects of Creep and Shrinkage on the Serviceability Limit State", Proceedings of Symposium, Concrete SructuresStimulators of Development, Dubrovnik, May, pp.623-632.

[9] Chiorino, M. A., 2010,"An Internationally harmonized Format for Time dependent Analysis of Concrete Structures", Proceedings IABSE-FIP Conference, Dubrovnik, May, V.1, pp.473-480.

[10] Comité Européen de Normalisation ( CEN), 2004a "Eurocode 2: Design of Concrete Structures-Part 11: General Rules and Rules for Buildings", European Standard BS EN 1992-1-1: 2004, European Committee for Standardization (CEN), Brussels, Belgium, $227 \mathrm{pp}$.

[11] Comité Européen de Normalisation ( CEN), 2004b "Eurocode 4: Design of Composite Steel and Concrete Strucures-Part 1-1:General Rules and Rules for Buildings", European Standard BS EN 1994-1-1: 1994, European Committee for Standardization (CEN), Brussels, Belgium, 118 pp.
[12] Cosenza, E., and Zandonini, R. 1999, Composite Construction. Structural Engineering Handbook, C. Wai-Fah, ed., CRC Press, Boca Raton, FL., pp. 1122.

[13] Dujmović, D.; Androić, B., and Lukačević,I., 2015, "Composite structures according to Eurocode 4", Wilhelm Ernst \& Sohn Verlag fur Architektur und Technische Wissenschaften, GmbH\& Co. KG, Berlin, Germany, 890 pp.

[14] Folić, R., and Zenuvović, D., 2009, "Composite Structures of Steel and Concrete, Faculty of Technical Sciences, Novi Sad, Serbija, 362 pp.

[15] Gardner, N. G., and Lockman, M. J., 2001, "Design Provisions for Drying Shrinkage and Creep of Normal Strength Concrete", ACl Materials Journal, March-April, pp. 159- 167.

[16] Jirasek, M., and Bažant, Z. P., 2002, Inelastic Analysis of Structures, Wiley and Sohns, LTD,

[17] Hoboken, NJ, $732 \mathrm{pp}$.

[18] Johnson, R.P., 2004, Composite Structures of Steel and Concrete, Blackwell, Oxford, UK, 230 pp.....

[19] Oehlers, D., and Bradford, M., 1999, Elementary behavior of composite steel and concrete stucrural members, Oxford, Butterworth-Heinemann, 279 pp.

[20] Partov, D., and Kantchev, V., 2009,"Timedependent analysis of composite steel-concrete beams using integral equation of Volterra, according EUROCODE-4“, Engineering Mechanics, V. 16, No 5, pp. 367-392.

[21] Partov, D., and Kantchev, V., 2011a, "Numerical analysis of composite steel-concrete section using integral equation of Volterra", Central. European Journal of Engineering, V.1, No.3, pp. 316-331.

[22] Partov, D., and Kantchev, V., 2011b,"Level of creep sensitivity in composite steel-concrete beams, according to $\mathrm{ACl}$ 209R-92 model, comparison with EUROCODE-4(CEB MC90-99)“, Engineering Mechanics, V. 18, No. 2, pp. 91-116.

[23] Partov, D., and Kantchev, V., 2014,"Gardner and Lockman model in Creep analysis of composite steel-concrete section ", ACl Structural Journal, Vol.111, No. 1,(January-February),, pp. 59-69.

[24] Šmerda, Z., and Krristek, VI., 1988, Creep and Shrinkage of Concrete Elements and Structures, Elsevier, New York, 296 pp.

[25] Vayas, I., and Iliopoulos, A., 2014, "Design of steelconcrete Composite Bridge to Eurocodes",

[26] CRC Press, Taylor\&Francis Group, Boca Raton, FL., 576 pp.

[27] Wang, C. Y., 2002, Steel and Composite Structures, Behavior and Design for Fire Safety, Taylor and Francis Group, London, UK, 352 pp.

\section{Conversation factors for the units}
$1 \mathrm{~mm}=0.03937 \mathrm{in}$
$1 \mathrm{~N}=0.2248 \mathrm{lbf}$
$1 \mathrm{kPa}=0.145 \mathrm{lbf} / \mathrm{in}^{2}$
$1 \mathrm{Mpa}=145 \mathrm{psi}$
$1 \mathrm{Nm}=8.8507 \mathrm{lbf}$.in.
$1 \mathrm{kN}=224.8 \mathrm{lbf}$. 


\section{COMPARATIVE ANALYSIS OF THE INFLUENCE OF CREEP OF CONCRETE COMPOSITE BEAMS OF STEEL - CONCRETE MODEL BASED ON VOLTERRA INTEGRAL EQUATION}

\section{Doncho PARTOV \\ Vesselin KANTCHEV}

The paper presents analysis of the stress-strain behaviour and deflection changes due to creep in statically determinate composite steel-concrete beam according to EUROCODE 2, ACl209R-92 and Gardner\&Lockman models. The mathematical model involves the equation of equilibrium, compatibility and constitutive relationship, i.e. an elastic law for the steel part and an integral-type creep law of Boltzmann Volterra for the concrete part considering the above mentioned models. On the basis of the theory of viscoelastic body of Maslov-Arutyunian-Trost-ZernaBažant for determining the redistribution of stresses in beam section between concrete plate and steel beam with respect to time "t", two independent Volterra integral equations of the second kind have been derived. Numerical method based on linear approximation of the singular kernel function in the integral equation is presented. Example with the model proposed is investigated.

Key words: steel-concrete section, integral equations, rheology, creep of concrete, redistribution of stresses, numerical method

\section{KOMPARATIVNA ANALIZA UTICAJA TEČENJA BETONA SPREGNUTE GREDE ČELIK - BETON MODELIMA ZASNOVANIM NA INTEGRALNOJ JEDNAČINI VOLTERRA}

\section{Doncho PARTOV \\ Vesselin KANTCHEV}

U radu je prikazana analiza odnosa napon-dilatacija i promene ugiba statički određene spregnuta grede čelik beton prema EVROCODU 2, ACl209R-92 i Gardner\&Lockman modelu. Razvijen j matematički model koji uključuje jednačine ravnoteže, kompatibilnosti i konstitutivne veze. Za čelični deo usvojeno je elastično ponašanje, a za betonski integralna veza saglasno zakonu Boltzmann - Volterra uvodeći u analizu napred pomenute modele. Na bazi Teorije visko-elastičnog tela i predloga autora: Maslov-Arutyunian-Trost-ZernaBažant, za određivanje preraspodela napona između betona i čelika, u presecima spregnute grede čelik beton tokom vremena " $t$ ". Formulisan je matematički model zasnovan na dve nezavisne integralne jednačine Volterra druge vrste. U numeričkom modelu koristi se linearna aproksimacija funkcije jezgra integralne jednačine. Primena modela je ilustrovana kroz primer $i$ primenu predloženog modela.

Ključne reči: spregnuti presek čelik - beton, integralne jednačine, veza napon - dilatacija, reologija, tečenje betona, numerička metoda 